\title{
The Role of Primary Motor Cortex (M1) Glutamate and GABA Signaling in L-DOPA-Induced Dyskinesia in Parkinsonian Rats
}

\author{
Dㅣ David Lindenbach, Melissa M. Conti, Corinne Y. Ostock, Jessica A. George, Adam A. Goldenberg, \\ Mitchell Melikhov-Sosin, Emily E. Nuss, and @Christopher Bishop \\ Behavioral Neuroscience Program, Department of Psychology, Binghamton University, State University of New York, Binghamton, New York 13901
}

Long-term treatment of Parkinson's disease with L-DOPA almost always leads to the development of involuntary movements termed L-DOPA-induced dyskinesia. Whereas hyperdopaminergic signaling in the basal ganglia is thought to cause dyskinesia, alterations in primary motor cortex (M1) activity are also prominent during dyskinesia, suggesting that the cortex may represent a therapeutic target. The present study used the rat unilateral 6-hydroxydopamine lesion model of Parkinson's disease to characterize in vivo changes in GABA and glutamate neurotransmission within M1 and determine their contribution to behavioral output. 6-Hydroxydopamine lesion led to parkinsonian motor impairment that was partially reversed by L-DOPA. Among sham-lesioned rats, L-DOPA did not change glutamate or GABA efflux. Likewise, 6-hydroxydopamine lesion did not impact GABA or glutamate among rats chronically treated with saline. However, we observed an interaction of lesion and treatment whereby, among lesioned rats, L-DOPA given acutely (1 d) or chronically (14-16 d) reduced glutamate efflux and enhanced GABA efflux. Site-specific microinjections into M1 demonstrated that L-DOPAinduced dyskinesia was reduced by $M 1$ infusion of a $D_{1}$ antagonist, an AMPA antagonist, or a $\mathrm{GABA}_{\mathrm{A}}$ agonist. Overall, the present study demonstrates that L-DOPA-induced dyskinesia is associated with increased M1 inhibition and that exogenously enhancing M1 inhibition may attenuate dyskinesia, findings that are in agreement with functional imaging and transcranial magnetic stimulation studies in human Parkinson's disease patients. Together, our study suggests that increasing M1 inhibitory tone is an endogenous compensatory response designed to limit dyskinesia severity and that potentiating this response is a viable therapeutic strategy.

Key words: dopamine; GABA; glutamate; L-DOPA; motor cortex; Parkinson's disease

Significance Statement

Most Parkinson's disease patients will receive L-DOPA and eventually develop hyperkinetic involuntary movements termed dyskinesia. Such symptoms can be as debilitating as the disease itself. Although dyskinesia is associated with dynamic changes in primary motor cortex physiology, to date, there are no published studies investigating in vivo neurotransmitter release in M1 during dyskinesia. In parkinsonian rats, L-DOPA administration reduced M1 glutamate efflux and enhanced GABA efflux, coincident with the emergence of dyskinetic behaviors. Dyskinesia could be reduced by local M1 modulation of $D_{1}, A M P A$, and $G_{A B A}$ receptors, providing preclinical support for the notion that exogenously blunting M1 signaling (pharmacologically or with cortical stimulation) is a therapeutic approach to the treatment of debilitating dyskinesias.

\section{Introduction}

Treatment of Parkinson's disease (PD) with the dopamine (DA) precursor L-DOPA is the most effective symptomatic therapy to restore movement, but long-term use typically results in the gradual development of hyperkinetic involuntary movements termed L-DOPA-induced dyskinesia (LID) (Ahlskog and 
Muenter, 2001; Cenci et al., 2011). Although striatal DA pathology is considered the primary cause of disease symptoms, the importance of cortical dysfunction in PD and LID has been increasingly recognized in recent years (for review, see Lefaucheur, 2005; Lindenbach and Bishop, 2013). Indeed, directly targeting the primary motor cortex (M1) with transcranial magnetic stimulation has shown promise in treating symptoms of PD and potentially LID (Fregni et al., 2005; Wagle-Shukla et al., 2007; Wu et al., 2008; Lefaucheur, 2009).

Although it has not been well characterized, PD patients appear to show significant catecholamine pathology in M1, with one study showing $25 \%-75 \%$ loss of DA fibers that was most extensive in the superficial cortical layers (Gaspar et al., 1991). Using the medial forebrain bundle 6-hydroxydopamine (6OHDA) rat model of $\mathrm{PD}$, our laboratory recently reported that 6-OHDA reduced DA fiber innervation of M1 by 75\% (Lindenbach et al., 2015).

Numerous neuroimaging studies have been conducted in PD patients, demonstrating that, relative to healthy controls, M1 blood oxygenation is increased when off-treatment while L-DOPA reduces M1 blood oxygen levels and glucose metabolism (Haslinger et al., 2001; Asanuma et al., 2006; Yu et al., 2007; Lindenbach and Bishop, 2013). A similar reduction in M1 blood flow was found in patients with LID susceptibility that were given a subthreshold dose of L-DOPA, suggesting that L-DOPA reduces hyperactivity in M1 (Hershey et al., 1998). The lone study on this topic in parkinsonian rats reported ambiguous results, finding that L-DOPA increased M1 blood flow while decreasing M1 glucose metabolism (Ohlin et al., 2012). Studies using rat models of LID consistently show that LID is associated with increased activity of immediate-early genes in M1, suggesting that at least some cell populations are hyperactive during LID (Ostock et al., 2011; Halje et al., 2012; Bastide et al., 2014; Lindenbach et al., 2015).

Analyses of gross physiological measurements, such as blood flow or immediate-early genes, may be difficult to interpret because animal models of PD consistently show abnormal firing patterns of both excitatory (glutamatergic) and inhibitory (GABAergic) cells in M1 (Parr-Brownlie and Hyland, 2005; Pasquereau and Turner, 2011; Brazhnik et al., 2012; Halje et al., 2012). In humans, patients actively displaying LID have greater M1 NMDA receptor activation than stable L-DOPA responders (Ahmed et al., 2011). Transcranial magnetic stimulation studies suggest that intracortical inhibition mediated by $\mathrm{M} 1 \mathrm{GABA}_{\mathrm{A}}$ and $\mathrm{GABA}_{\mathrm{B}}$ receptors is reduced in PD patients off-treatment and restored by L-DOPA (Ridding et al., 1995; Lefaucheur, 2005). Because dyskinesia can be modified by local delivery of a $5-\mathrm{HT}_{1 \mathrm{~A}}$ agonist or a $\mathrm{D}_{1}$ antagonist, it appears that neurotransmitter signaling in M1 can causally contribute to the expression of LID behavior, and targeting such signaling may be therapeutically valuable (Ostock et al., 2011; Halje et al., 2012).

Despite accumulating circumstantial evidence that M1 amino acid signaling is involved in PD and LID symptoms, this has not been directly tested. At present, it is unclear how M1 glutamate and GABA efflux are involved in, or contribute to, the behavioral response to L-DOPA. For the first time, the present study used in vivo microdialysis in awake-behaving animals to examine endogenous changes in M1 glutamate and GABA after L-DOPA was administered to sham or 6-OHDA-lesioned rats. This approach was complemented with M1 microinjections to causally implicate specific M1 receptors in the pathophysiology of LID and the pro-motor effects of L-DOPA.

\section{Materials and Methods}

\section{Animals}

All experiments used male Sprague Dawley rats (Taconic Farms; RRID: RGD_5508397) that were 9-11 weeks old at the start of the experiment $(N=118)$. Rats were kept in plastic cages and given free access to water and standard laboratory rat food. The colony room was maintained at $22^{\circ} \mathrm{C}-23^{\circ} \mathrm{C}$ on a $12 \mathrm{~h}$ light/dark cycle (lights on 0700 to 1900 ) with experiments performed during the light cycle. Throughout the study, rats were cared for in full accordance with the guidelines of the Institutional Animal Care and Use Committee of Binghamton University and the most current National Institutes of Health Guide for the Care and Use of Laboratory Animals.

\section{Surgeries}

Sham and active lesions were created by infusing vehicle and 6-OHDA, respectively, into the medial forebrain bundle. Rats received either bilateral sham lesions ("Sham"; Experiment 1 only) or a unilateral 6-OHDA lesion and a unilateral sham lesion ("Lesion"; Experiments 1 and 2). For analgesic purposes, rats were given buprenorphine $(0.03 \mathrm{mg} / \mathrm{kg})$ immediately before surgery and $24 \mathrm{~h}$ after surgery. Rats were anesthetized with isoflurane ( $1 \%-3 \%$ for $75-120 \mathrm{~min}$ ) mixed with oxygen $(1.0 \mathrm{~L} / \mathrm{min})$. The following coordinates relative to bregma were used to target the medial forebrain bundle according to the rat brain atlas of Paxinos and Watson (1998): anteroposterior $-1.8 \mathrm{~mm}$, mediolateral $\pm 2.0 \mathrm{~mm}$, dorsoventral -8.6 , with the skull surface set to flat. A syringe with 26 gauge needle (Hamilton) was lowered into the target site and 6-OHDA $(12 \mu \mathrm{g})$ or vehicle was injected at a constant flow rate of $2 \mu \mathrm{l} / \mathrm{min}$ for $2 \mathrm{~min}$. The needle was withdrawn 5 min later.

In Experiment 1, rats were fitted with bilateral microdialysis guide cannulae (Synaptech) in M1 at the following coordinates relative to bregma: anteroposterior $1.6 \mathrm{~mm}$, mediolateral $\pm 2.3 \mathrm{~mm}$, dorsoventral -0.6 $\mathrm{mm}$. In Experiment 2, bilateral microinjection guide cannulae (22 gauge, Plastics One) were placed in M1 (relative to bregma): anteroposterior 1.6 $\mathrm{mm}$, mediolateral $\pm 2.6 \mathrm{~mm}$, dorsoventral $-0.8 \mathrm{~mm}$. To stabilize cannulae, four jeweler's screws were placed in the skull and fixed with dental acrylic.

\section{Drugs}

All drugs given systemically were delivered at a volume of $1 \mathrm{ml} / \mathrm{kg}$ and injected intraperitoneally, except for L-DOPA, which was given subcutaneously. Buprenorphine hydrochloride (Hospira) was dissolved in saline. 6-OHDA hydrobromide (Sigma-Aldrich) and L-DOPA methyl ester hydrochloride (Sigma-Aldrich) were dissolved in saline with $0.1 \%$ ascorbic acid. Two doses of L-DOPA were used ( 4 and $6 \mathrm{mg} / \mathrm{kg}$ ), but the peripheral decarboxylase inhibitor benserazide hydrochloride (SigmaAldrich) was always coadministered at a constant dose of $15 \mathrm{mg} / \mathrm{kg}$.

\section{Abnormal involuntary movements (AIMs) test}

The AIMs test is a metric of dyskinesia. Rats were monitored for AIMs using a procedure modified from Cenci and Lundblad (2007) and described in detail by Lindenbach et al. (2011). Rats were observed in clearplastic cylinders and were rated by a trained observer ( $\geq 95 \%$ reliability), every $10 \mathrm{~min}$ for $180 \mathrm{~min}$. During each rating period, individual dyskinesia severity scores ranging from 0 (not present) to 4 (severe and not interruptible) were given for axial, limb, and orolingual dyskinesias. The threes AIMs subtypes were summed to create a single AIMs score for data analysis.

\section{Forepaw adjusting steps (FAS) test}

The FAS test is a measure of akinesia, a cardinal symptom of PD (Jankovic, 2008). Rats with $>80 \%$ unilateral DA depletion perform poorly on the test with the lesioned side of the body (Chang et al., 1999). L-DOPA reduces this deficit so the test can be used to determine whether any additional adjunct treatment is impacting the efficacy of L-DOPA (Eskow et al., 2007). To perform the test, an experimenter blind to treatment condition held the rat's hindlimbs and one forelimb such that the free forelimb was forced to bear the rat's body weight. Rats were moved laterally for $90 \mathrm{~cm}$ over $10 \mathrm{~s}$ while another experimenter counted the number of steps taken in each direction (toward or away from a rat's midline). Each FAS test consisted of three trials in each direction, for a 
A

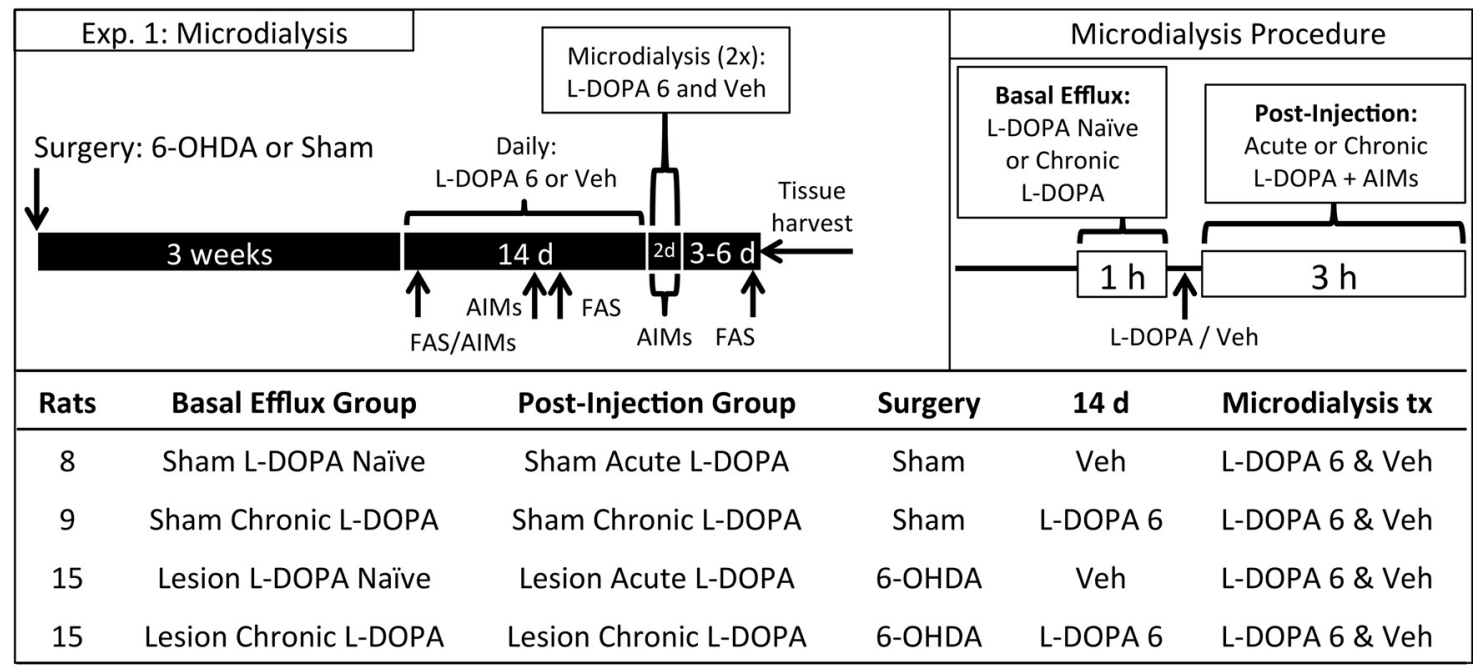

B

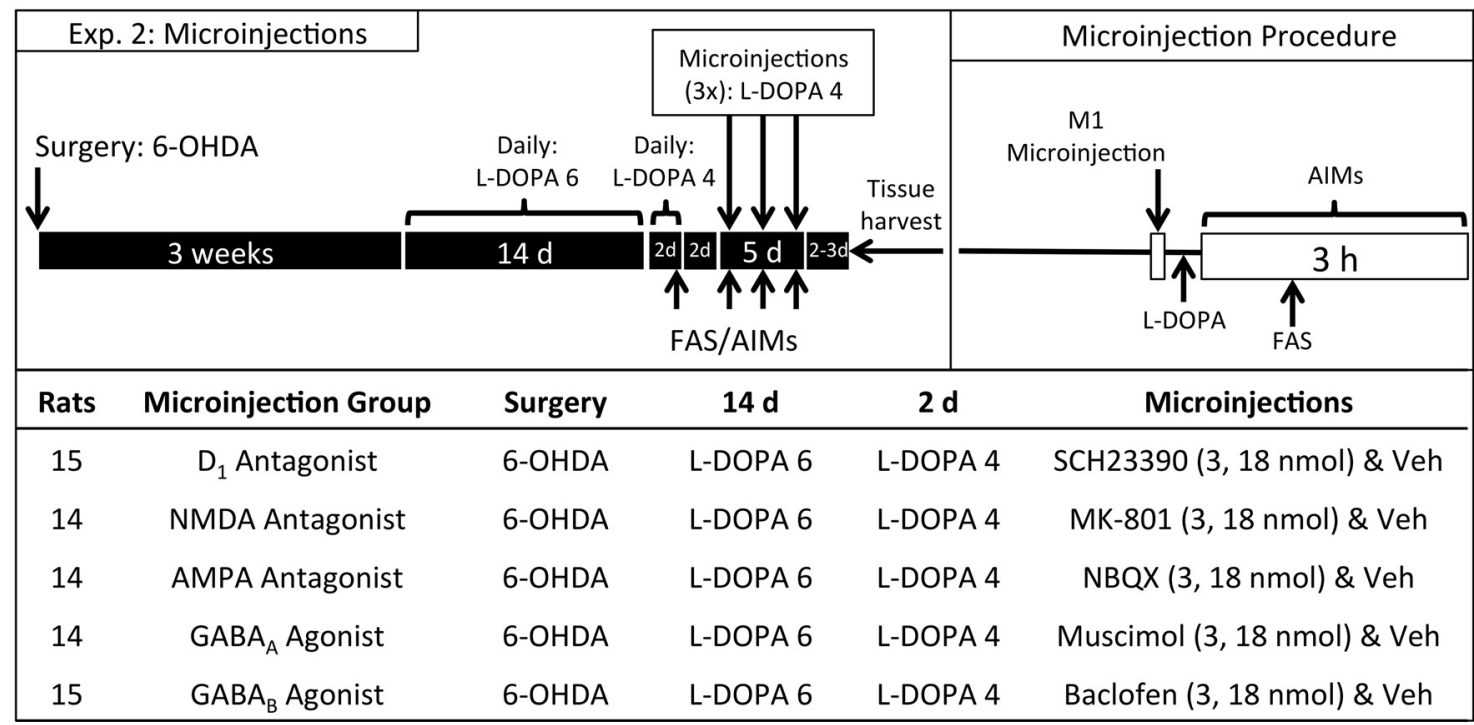

Figure 1. Schematic illustrating the experimental timeline. A, All rats received bilateral motor cortex microdialysis guide cannulae and underwent 6-OHDA lesion or sham surgery. After recovery, rats were treated with daily L-DOPA or vehicle (Veh), during which time motor impairment was scored using the FAS test and dyskinesia was rated with the AIMs scale. Microdialysis for glutamate and GABA was performed over $2 \mathrm{~d}$. Long-term changes in basal glutamate and GABA efflux were measured on the first day of dialysis before drug injection. Rapid changes due to drug treatment were measured after L-DOPA or Veh injection on both days of dialysis. B, All rats received bilateral microinjection guide cannulae and a 6-OHDA lesion. After recovery, rats were treated with daily L-DOPA and behaviorally examined for motor impairment and dyskinesia. Later, rats received $\mathrm{M} 1$ microinjections (on $3 \mathrm{~d}$ over a $5 \mathrm{~d}$ period) immediately before L-DOPA treatment and were subsequently rated for FAS and AIMs.

total of six trials per limb and 12 trials per rat. To verify parkinsonian behavioral status and reversal of deficit by L-DOPA, we also analyzed "percent intact" stepping: this score is derived by dividing the total steps with the lesioned forelimb by steps with the nonlesioned forelimb. Fewer steps or a lower percent intact indicate a more severe parkinsonian impairment.

Experiment 1: lesion and L-DOPA-induced changes in M1 glutamate and GABA efflux

Procedure. The effects of acute and chronic L-DOPA administration on M1 amino acid efflux were examined in separate cohorts of rats $(n=47$; Fig. 1A). During surgery, rats received sham or DA lesions to the medial forebrain bundle and bilateral M1 microdialysis cannulae were implanted. Testing began 3 weeks after lesion $( \pm 2 \mathrm{~d})$ when we measured off-drug motor impairment with FAS. Rats with a 6-OHDA lesion were only probed for microdialysis if they manifested significant parkinsonian symptoms, defined as displaying $<60 \%$ intact stepping (inclusion rate: $95 \%$ of rats). Beginning the next day (day 1), rats were given 2 weeks of daily injections with vehicle (for rats in the acute L-DOPA condition) or $6 \mathrm{mg} / \mathrm{kg}$ L-DOPA (for rats in the chronic L-DOPA condition). During this period, dyskinesia development was monitored on day 1 and day 8 with the AIMs scale (for $180 \mathrm{~min}$ ). Lesion-induced impairment was assessed with the FAS test on day 1 and day 10 at 60-65 min after injection (FAS data on day 1 include only 34 of 47 rats).

Microdialysis probes were implanted bilaterally the evening before testing. In 11 of 47 rats, one probe membrane failed before/during testing, meaning that only one hemisphere could be analyzed. We used Synaptech probes with $2 \mathrm{~mm}$ shaft, $360 \mu \mathrm{m}$ outer diameter, and $20 \mathrm{kDa}$ pore permeability. Microdialysis was performed on days 15 and 16 with rats receiving one treatment each day during microdialysis (L-DOPA 6 $\mathrm{mg} / \mathrm{kg}$ and vehicle; within-subjects, order counterbalanced). To main- 
tain "daily" L-DOPA treatment, rats treated with chronic L-DOPA (days $1-14)$ that received vehicle on day 15 during microdialysis were given L-DOPA $6 \mathrm{mg} / \mathrm{kg}$ immediately after microdialysis.

Microdialysis sessions took place during the light cycle, with samples collected every $20 \mathrm{~min}$ for $5 \mathrm{~h}$ between 1000 and $1700 \mathrm{~h}$. Probes were connected to a syringe pump (model 400, CMA Microdialysis) set at a 2 $\mu \mathrm{l} / \mathrm{min}$ flow rate. The flow was turned on, and rats were habituated to the microdialysis chamber for $2-3 \mathrm{~h}$ before samples were collected. Baseline samples were collected at least $20 \mathrm{~h}$ after last injection with L-DOPA or vehicle. Six pretreatment samples were taken every $20 \mathrm{~min}$ for $120 \mathrm{~min}$, but in most cases only the final three baselines were used for data analysis. If the final three samples were not all within $50 \%$ of their collective mean, we substituted in earlier baselines; overall, baseline substitution was performed for $4 \%$ of glutamate samples and $6 \%$ of GABA samples. If two substitutions could not stabilize baselines, the entire microdialysis run was discarded ( $4 \%$ of glutamate runs, and $7 \%$ of GABA runs).

After baseline samples were collected, rats were injected with L-DOPA $(6 \mathrm{mg} / \mathrm{kg}$ ) or vehicle, and samples were taken every $20 \mathrm{~min}$ for $180 \mathrm{~min}$ after treatment. Rats were monitored for AIMs every 10 min after drug injection. Differences in basal amino acid efflux resulting from DA lesion and/or chronic L-DOPA were determined by comparing raw dialysate concentrations during baseline on the first day of microdialysis. The effects of L-DOPA on M1 amino acid efflux were assessed by dividing treatments samples by the mean of the baseline samples (from that day), yielding "percent baseline."

After testing on day 16, rats were returned to their home cages and left untreated for 3-6 d as a drug washout period. The FAS test was performed again and immediately afterward, rats were decapitated and the brains removed. The posterior striata was dissected for high performance liquid chromatography (HPLC) analysis of DA content to verify lesion severity. The anterior forebrain was flash-frozen in 2-methylbutane and cut into $20 \mu \mathrm{m}$ slices on a cryostat. Sections were stained with $0.1 \%$ cresyl violet acetate (Sigma-Aldrich), and light microscopy was used to examine cannula placements (see Fig. $3 A, B$ ).

Chromatography of M1 dialysate. HPLC for amino acids was executed based on a protocol by Rowley et al. (1995) using methods optimized for our laboratory and equipment (Dupre et al., 2011, 2013). Dialysate samples were analyzed for extracellular glutamate and GABA levels. aCSF was prepared as follows (in $\mathrm{mm}$ ): $128.0 \mathrm{NaCl}, 2.5 \mathrm{KCl}, 1.3 \mathrm{CaCl}_{2}, 2.1 \mathrm{MgCl}_{2}$, $0.9 \mathrm{NaH}_{2} \mathrm{PO}_{4}, 2.0 \mathrm{Na}_{2} \mathrm{HPO}_{4}$, and 1.0 glucose, brought to a $\mathrm{pH}$ of 7.4 with $\sigma$-phosphoric acid. To make the amino acids electrochemically detectable, $27 \mu \mathrm{l}$ of sample was combined with $10 \mu \mathrm{l}$ of a $\sigma$-phthaldialdehyde/ $\beta$-mercaptoethanol mixture; the resulting mixture was injected into the column by an autosampler. The mobile phase consisted of $100 \mathrm{~mm}$ $\mathrm{Na}_{2} \mathrm{HPO}_{4}$ with $22 \%$ methanol and $3.5 \%$ acetonitrile, filtered through 0.2 $\mu \mathrm{m}$ nylon membrane filter, and adjusted to a $\mathrm{pH}$ of 6.75 with $\mathrm{NaOH}$.

As working standards, we used $10^{-5}$ to $10^{-8} \mathrm{M}$ standards for glutamate. Because cortical concentrations of GABA are lower than glutamate, the GABA regression line was created using the $10^{-6}$ to $10^{-9} \mathrm{M}$ standards and also incorporated aCSF $(0 \mathrm{M})$. In vitro recovery was performed on a subset of probes before and after implantation for microdialysis: values appeared stable for glutamate ( $15.5 \%$ before, $14.6 \%$ after) and GABA ( $10.3 \%$ before, $10.2 \%$ after). Further analysis showed that sample concentrations were highly consistent between probes and samples (Average $r^{2}=0.9993$, when $\mathrm{X}=$ concentration of standard in which probe was embedded and $\mathrm{Y}=$ sample concentration as determined by HPLC).

Examining our ultimate control rats (sham-lesioned, vehicle-treated), glutamate concentration averaged $484 \mathrm{pg} / \mu \mathrm{l}$ (corrected for in vitro probe recovery: $3134 \mathrm{pg} / \mu \mathrm{l}$ ), whereas GABA averaged $1.4 \mathrm{pg} / \mu \mathrm{l}$ (corrected for in vitro probe recovery: $13.2 \mathrm{pg} / \mu \mathrm{l}$ ). These values are similar to published reports where microdialysis was performed in M1 of healthy Sprague Dawley rats (La Bella et al., 2000; Mabrouk et al., 2014).

Experiment 2: contribution of $M 1$ receptor signaling to behavioral output after systemic L-DOPA

Procedure. This experiment analyzed the effects of M1 pharmacological intervention on the behavioral manifestation of LID and L-DOPA efficacy $(n=71$; Fig. $1 B)$. During surgery, all rats received a unilateral
6-OHDA lesion to the medial forebrain bundle and bilateral M1 microinjection cannulae.

Testing began 3 weeks after surgery $( \pm 2 \mathrm{~d})$. Rats were given daily L-DOPA $(6 \mathrm{mg} / \mathrm{kg})$ injections for $14 \mathrm{~d}$ to prime them for maximal LID severity. On three occasions, rats were habituated to the microinjection procedure, including light restraint with a towel and head cap manipulation, mimicking microinjector insertion. On days 15 and 16, rats were given the test dose of L-DOPA ( $4 \mathrm{mg} / \mathrm{kg})$. Before L-DOPA injection on day 16, rats were tested with FAS to determine lesion-induced motor impairment. For rats with a 6-OHDA lesion, inclusion was based on manifesting significant parkinsonian symptoms, defined as displaying $<60 \%$ intact stepping (inclusion rate: $93 \%$ of rats). After L-DOPA 4 $\mathrm{mg} / \mathrm{kg}$ injection, rats were monitored for AIMs; and only those that displayed $\geq 15$ total AIMs over 180 min were included in AIMs testing (inclusion rate: $78 \%$ of rats). A lower dose of L-DOPA $(4 \mathrm{mg} / \mathrm{kg}$ ) was chosen for this experiment so that it would be possible to detect increases or decreases in LID severity with the AIMs scale (Ostock et al., 2015).

After day 16 behavioral testing, rats were left untreated for $2 \mathrm{~d}$. Microinjections were performed on days 18, 20, and 22. A 28 gauge microinjector (Plastics One) was cut such that the injector tip would extend 1 $\mathrm{mm}$ ventral from the guide shaft. Drugs were dissolved in saline or $\mathrm{dH}_{2} \mathrm{O}$, and an injector was used to infuse $1 \mu \mathrm{l}$ of fluid at a flow rate of 0.25 $\mu \mathrm{l} / \mathrm{min}$. The injector remained in place for $5 \mathrm{~min}$ after flow cessation. We estimated the spread of fluid within M1 with rats from the experiment that did not meet behavioral criteria. Rats were microinjected with cresyl violet $\left(1 \mu \mathrm{g}\right.$ in $\left.1 \mu \mathrm{l} \mathrm{dH_{2 }} \mathrm{O}\right)$ using the same procedures as above and killed 15-75 min later. Upon histological examination, no cresyl violet was observed outside of M1 as defined by Paxinos and Watson (1998).

All rats received microinfusions of one the following compounds ( 0,3 , or $18 \mathrm{nmol}$ ) immediately before L-DOPA $(4 \mathrm{mg} / \mathrm{kg})$ : the $\mathrm{D}_{1}$ antagonist SCH23390 (Sigma-Aldrich), the NMDA antagonist MK-801 (SigmaAldrich), the AMPA antagonist NBQX (Enzo Life Sciences), the GABA agonist muscimol (Enzo Life Sciences), or the $\mathrm{GABA}_{\mathrm{B}}$ agonist baclofen (Enzo Life Sciences). All drugs were dissolved in saline, except NBQX, which was dissolved in $\mathrm{dH}_{2} \mathrm{O}$. Each rat received three total microinfusions consisting of the same drug with doses given in a counterbalanced order. Doses of 3 and $18 \mathrm{nmol}$ were selected based on amounts required to deliver to M1 to elicit behavioral changes (Martin, 1991; St-Pierre and Bédard, 1994; Carlezon et al., 1996; Kawaguchi and Simon, 1997; Sorg et al., 2001). After L-DOPA, AIMs was monitored every $10 \mathrm{~min}$ for the next $180 \mathrm{~min}$; the FAS test was performed 65 min after L-DOPA.

Rats were left untreated for 2-3 d after the last microinjection before being decapitated for neurochemical and histological analyses. The posterior striata was dissected for HPLC assay of DA content. The anterior forebrain was flash frozen, cut on a cryostat, and stained with cresyl violet to examine the microinjection tract.

Postmortem chromatography of striatal tissue. To verify DA lesion, HPLC coupled to electrochemical detection was performed on striatal tissue according to a protocol for monoamine analysis by Kilpatrick et al. (1986) and described by Dupre et al. (2011). Tissue was homogenized in ice-cold perchloric acid $(0.1 \mathrm{M})$ with $1 \%$ ethanol and $0.02 \%$ EDTA. The homogenates were spun for $30 \mathrm{~min}$ at $14,000 \times g$ with the temperature maintained at $4^{\circ} \mathrm{C}$. Aliquots of supernatant were analyzed for abundance of DA. Samples were separated using a mobile phase composed of $90 \mathrm{~mm}$ $\mathrm{NaH}_{2} \mathrm{PO}_{4}, 50 \mu \mathrm{M}$ EDTA, $1.7 \mathrm{~mm}$ octane sulfonic acid, and 10\% acetonitrile, adjusted to $\mathrm{pH} 3.0$ with $\sigma$-phosphoric acid. Standards were run across a range of $10^{-6}$ to $10^{-9} \mathrm{M}$, and the corresponding regression line was used to estimate DA content in striatal samples. Values were adjusted to wet tissue weights and reported as pg (of DA) per milligrams (of tissue).

\section{Statistical analyses}

Statistical analysis was performed with SPSS version 20 (IBM; RRID: SCR_002865) using $\alpha=0.05$. Effect sizes for $F$ tests are reported as partial $\eta$ squared $\left(\eta_{\mathrm{p}}^{2}\right)$, which measures the fraction of variance independently predicted by a single effect (range $0-1$ ). Because the AIMs scale has ordinal intervals, nonparametric analyses were used.

Experiment 1: statistical tests. Motor performance data from the FAS test were analyzed with a $2 \times 2 \times 4$ mixed-model ANOVA: Lesion 
(6-OHDA or Sham $) \times$ Treatment (L-DOPA or vehicle $) \times$ Day (Baseline, Day 1, Day 10, Post). Dyskinesia scores (AIMs) were analyzed with three nonparametric tests: Mann-Whitney $U$ (for between-subjects contrasts), the Friedman test (for within-subjects omnibus tests), and the Wilcoxon signed-rank test (for within-subjects contrasts). To examine basal amino acid efflux before treatment, we used a $2 \times 3$ ANOVA: Priming (L-DOPA Naive or Chronic L-DOPA) $\times$ Lesion (Sham, Ipsilateral or Contralateral [to Lesion]). Subsequent to treatment, changes in glutamate and GABA were analyzed with a $2 \times 3 \times 2 \times 9$ mixed-model ANOVA: Priming (Acute or Chronic L-DOPA) $\times$ Lesion (Sham, Ipsilateral or Contralateral [to Lesion] $) \times$ Treatment (L-DOPA or vehicle) $\times$ Time $(9$ samples). Last, Pearson correlations determined whether changes in M1 GABA or glutamate efflux predicted dyskinesia expression.

Experiment 2: statistical tests. Effects of microinjection on motor performance were analyzed with a $2 \times 3$ repeated-measures ANOVA: Hemisphere (Lesion or Intact) $\times$ Treatment (vehicle, 3 and $18 \mathrm{nmol}$ of drug). Changes in dyskinesia scores as a function of M1 microinjection were analyzed with the Friedman test and followed up with Wilcoxon-signed rank contrasts if appropriate.

If significant heteroschedasticity was demonstrated with Mauchley's test of sphericity (for ANOVAs) or Levene's test for inequality of variance (for $t$ tests), degrees of freedom were adjusted with Huyhn-Feldt corrections or Welch's $t$ test, respectively, and are reported as fractions. If a given analysis was between-subjects and analyzed with parametric statistics, data $>2.5$ SDs from the group mean were considered outliers and discarded.

\section{Results}

\section{Experiment 1: lesion and L-DOPA-induced changes in M1} glutamate and GABA efflux

\section{Effect of lesion on striatal monoamine content}

Dopamine lesion was confirmed in striatal tissue via HPLC. Rats with a 6-OHDA lesion had 99\% less striatal DA ipsilateral to lesion as contralateral to lesion ( $48 \mathrm{vs} 6491 \mathrm{pg} / \mathrm{mg} ; t_{(23)}=11.76$, $p<0.001)$. There was no difference in striatal DA between sham rats and 6-OHDA-lesioned rats contralateral to lesion $\left(t_{(41)}=\right.$ $1.31, p=0.198)$, verifying the unilateral nature of the lesion. DA content was equivalent between rats assigned to receive acute or chronic L-DOPA $\left(t_{(22)}=1.05, p=0.307\right)$.

\section{Motor performance}

To verify parkinsonian motor deficits and their reversal by L-DOPA, the FAS test was performed before, during, and after daily treatments. Importantly for our planned comparisons, there was a significant Lesion $\times$ Treatment $\times$ Day interaction $\left(F_{(3,129)}=7.90, p<\right.$ 0.001, $\left.\eta_{\mathrm{p}}^{2}=0.155\right)$. 6-OHDA-lesioned rats treated with vehicle showed equivalent stepping on all days (Fig. 2A). Compared with baseline, lesioned rats given chronic L-DOPA $(6 \mathrm{mg} / \mathrm{kg})$ showed increased stepping on day 1 and day 10 of treatment (both $p<0.001$ ); as is sometimes the case after chronic L-DOPA treatment (Zhuang et al., 2013), these rats maintained a degree of motor improvement when tested after microdialysis after L-DOPA had been withdrawn for 3-6d $(p=0.001)$.

\section{LID development and expression}

Among rats given chronic L-DOPA, AIMs increased from day 1 to day 8 of L-DOPA, demonstrating that rats developed dyskinesia of increasing severity over time (Fig. $2 B ; Z=3.23, p=0.001$ ). For the same rats, during microdialysis (day 15 or 16 of L-DOPA), there was a reduction in AIMs during microdialysis compared with day 8 of L-DOPA $(Z=2.16, p=0.031)$. Although not directly tested in this experiment, we have observed that a change in context can affect AIMs scores (i.e., testing in the microdialysis room vs the standard AIMs rating room).

Next, we verified that there was no significant different in AIMs scores on the first exposure to L-DOPA between rats as- signed to the chronic L-DOPA group and rats assigned to the acute L-DOPA group $(Z=1.18, p=0.238)$. As expected, during microdialysis, rats treated with chronic L-DOPA showed greater dyskinesia than rats given acute L-DOPA (see Fig. $2 C ; Z=3.23$, $p=0.001$ ). Analyzing the time course, AIMs was greater for chronic versus acute L-DOPA from 30 to $110 \mathrm{~min}$ after treatment (all $p \leq 0.011$ ).

\section{Basal amino acid efflux}

We examined changes in basal (off drug) glutamate and GABA efflux to determine whether 6-OHDA lesion and/or L-DOPA priming were inducing protracted changes in M1 GABA and glutamate levels.

Omnibus ANOVA for basal glutamate efflux revealed that the Priming $\times$ Lesion interaction was on the cusp of the significance threshold $\left(F_{(2,75)}=3.09, p=0.052, \eta_{\mathrm{p}}^{2}=0.076\right)$. Glutamate levels were decreased ipsilateral to lesion for rats given chronic L-DOPA (Fig. $3 C$ ), with significant reductions compared with contralateral to lesion $\left(t_{(13.5)}=3.10, p=0.008\right)$ and compared with L-DOPA naive rats ipsilateral to lesion $\left(t_{(15.1)}=2.38, p=0.031\right)$.

Analyzing basal GABA efflux, ANOVA revealed a significant Priming $\times$ Lesion interaction $\left(F_{(2,69)}=4.95, p=0.010, \eta_{\mathrm{p}}^{2}=\right.$ $0.125)$. As seen in Figure $3 D$, ipsilateral to 6-OHDA lesion, rats given chronic L-DOPA showed increased GABA efflux relative to acute L-DOPA $\left(t_{(13.0)}=2.22, p=0.044\right)$ and relative to chronic $\mathrm{L}$-DOPA in sham rats $\left(t_{(11.7)}=2.41, p=0.033\right)$. Increased GABA was also seen after chronic L-DOPA contralateral to lesion, compared with both L-DOPA naive rats contralateral to lesion $\left(t_{(13.3)}=3.32, p=0.005\right)$ and compared with sham rats given chronic L-DOPA $\left(t_{(12.2)}=3.31, p=0.006\right)$.

\section{Glutamate release after $L-D O P A$}

Next, we analyzed the effects of L-DOPA on glutamate efflux for $3 \mathrm{~h}$ after drug administration because this is the duration of the behavioral response to L-DOPA $6 \mathrm{mg} / \mathrm{kg}$. Results of $2 \times$ $3 \times 2 \times 9$ ANOVA revealed that two of the four possible third-order effects were significant: Lesion $\times$ Treatment $\times$ Time $\left(F_{(16,1120)}=3.08, p<0.001, \eta_{\mathrm{p}}^{2}=0.042\right)$ and Priming $\times$ Lesion $\times$ Time $\left(F_{(16,1120)}=2.09, p=0.007, \eta_{\mathrm{p}}^{2}=0.029\right)$. The four-way interaction (Priming $\times$ Lesion $\times$ Treatment $\times$ Time) was near the threshold of significance $\left(F_{(16,1120)}=1.57\right.$, $p=0.069, \eta_{\mathrm{p}}^{2}=0.022$ ).

Based on these interactions, we performed a time series analysis. Among sham rats, L-DOPA did not impact glutamate efflux (Fig. 4A). Ipsilateral to lesion, acute administration of L-DOPA decreased glutamate efflux, with a statistically significant reduction in glutamate at the 20,80 , and $120-180$ time points (Fig. $4 B$; all $p \leq 0.043$ ). Among rats chronically exposed to L-DOPA, injection with L-DOPA during microdialysis did not alter glutamate levels ipsilateral to lesion but did cause an increase in glutamate contralateral to lesion at the 40 and $80 \mathrm{~min}$ time points (Fig. $4 C$; both $p \leq 0.034$ ).

Next, we performed a correlation to determine the extent to which AIMs scores (in Fig. 2C) were associated with changes in glutamate efflux. Because two AIMs scores were taken for every one microdialysis sample, the average of two AIMs ratings was correlated with a single dialysis sample. Ipsilateral to lesion, for rats given acute L-DOPA, we found a marginally significant positive correlation between percent baseline glutamate efflux and AIMs scores (Fig. $5 A ; r^{2}=0.039, p=0.034$ ). Surprisingly, AIMs scores showed a stronger positive correlation with M1 glutamate efflux contralateral to lesion (Fig. $5 B ; r^{2}=0.167, p<0.001$ ). There was no correlation between AIMs scores and glutamate efflux for rats given chronic L-DOPA (Fig. 5C,D). 
A

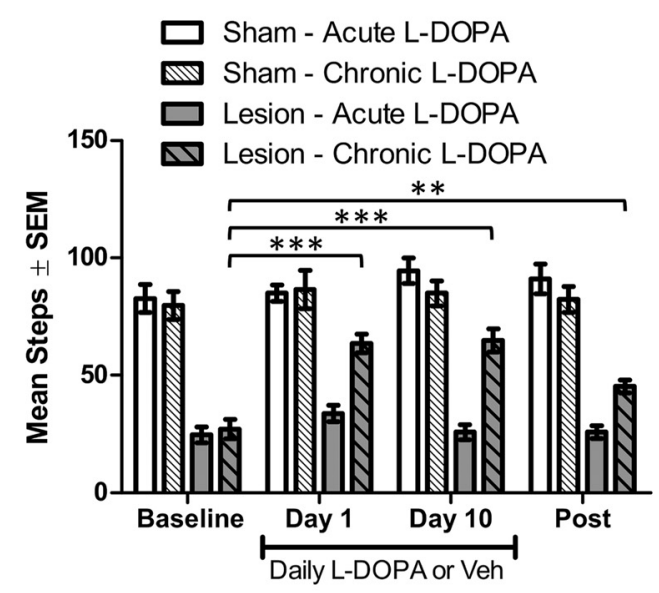

B

\section{L-DOPA-induced Dyskinesia Across Days}

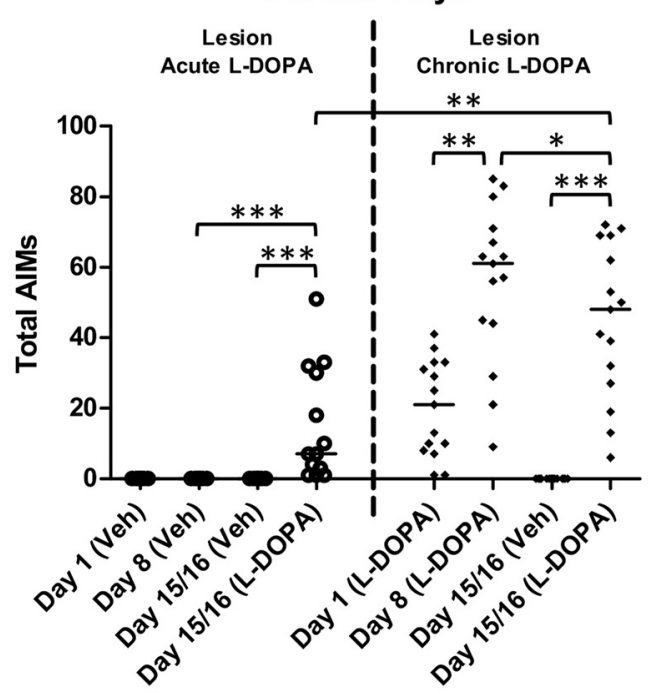

C Dyskinesia During Microdialysis

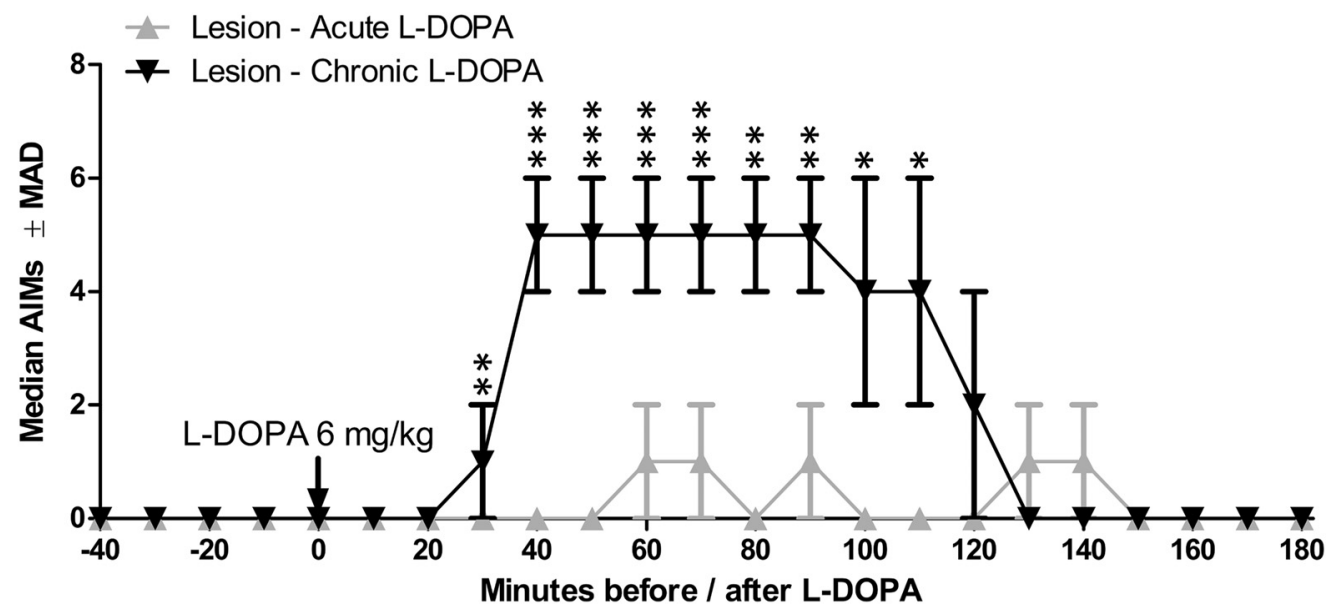

Figure 2. Effects of lesion and L-DOPA on motor performance and the development of dyskinesia for rats in Experiment 1 ( $n=8-15$ per group). Rats were treated for $14 \mathrm{~d}$ with daily L-DOPA 6 $\mathrm{mg} / \mathrm{kg}$ ("Chronic") or vehicle (Veh; "Acute"). On each of the next $2 \mathrm{~d}$, microdialysis was performed. Importantly, rats in the "acute" condition only received one injection of L-DOPA (on day 15 and 16 during microdialysis). $A$, Parkinsonian motor impairment was assessed by analyzing the number of steps taken with the lesioned forepaw before drug treatment (baseline), on days 1 and 10 of treatment, and after treatment had concluded (post). B, Dyskinesia was quantified using the AIMs scale on days 1 and 8 of daily treatments as well as during microdialysis on days 15 and 16 . Horizontal bars represent median scores for each group. C, Dyskinesia during microdialysis for lesioned rats given L-DOPA. AIMs data are displayed as medians with median absolute deviation (MAD) as the error term. ${ }^{*} p<0.05 .{ }^{* *} p<0.01 .{ }^{* *} p<0.001$.

As another means of visualizing the correlation between a change in glutamate efflux and AIMs scores among rats given acute L-DOPA, we performed a median split, grouping rats by high/low dyskinesia severity (Fig. 5E). Inferential statistics were not performed on this dataset because of the reduced sample size. Examining Figure 5F, changes in M1 glutamate after L-DOPA appeared to depend on behavioral output. Rats in the low AIMs group showed a precipitous decline in glutamate ipsilateral to lesion. Conversely, rats in the high AIMs group showed less of a decline in glutamate ipsilateral to lesion but did show a consistent increase in glutamate contralateral to lesion.

GABA release after $L-D O P A$

Next, we examined changes in GABA efflux caused by L-DOPA. GABA levels in the neocortex are relatively low and can be difficult to measure via HPLC due to the long retention time of GABA in the chromatography column (Rowley et al., 1995; Rea et al.,
2005). Whereas all GABA baselines were above our threshold of detection (threshold $=0.043 \mathrm{pg} / \mu \mathrm{l}$; minimum observed $=0.079$ $\mathrm{pg} / \mu \mathrm{l})$, runs near our threshold of detection often showed highly variable changes in percent baseline. To obviate this issue, we only analyzed percent baseline changes in GABA for rats that had an average GABA baseline of at least $0.250 \mathrm{pg} / \mu \mathrm{l}(93 \%$ of all runs).

GABA efflux was evaluated first with an omnibus ANOVA, which revealed a significant interaction of Time $\times$ Treatment $\left(F_{(8,880)}=1.98, p=0.046, \eta_{\mathrm{p}}^{2}=0.018\right)$ as well as Time $\times$ Treatment $\times$ Lesion $\left(F_{(16,880)}=1.95, p=0.014, \eta_{\mathrm{p}}^{2}=0.034\right)$. Time point comparisons were performed based on these interactions. Among sham rats, treatment with L-DOPA $(6 \mathrm{mg} / \mathrm{kg})$ did not affect GABA efflux (Fig. 6A). Ipsilateral to lesion, acute L-DOPA caused a small and transitory decrease in GABA in the first $20 \mathrm{~min}$ after injection (Fig. $6 B ; p=0.003$ ). Chronic L-DOPA caused a 
A

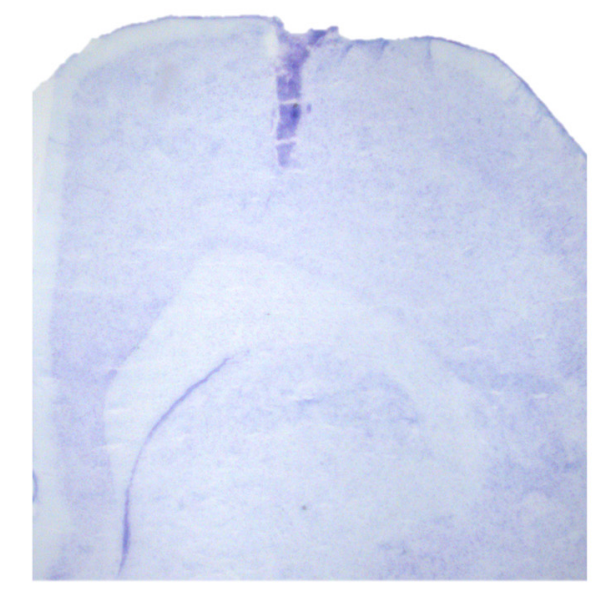

C

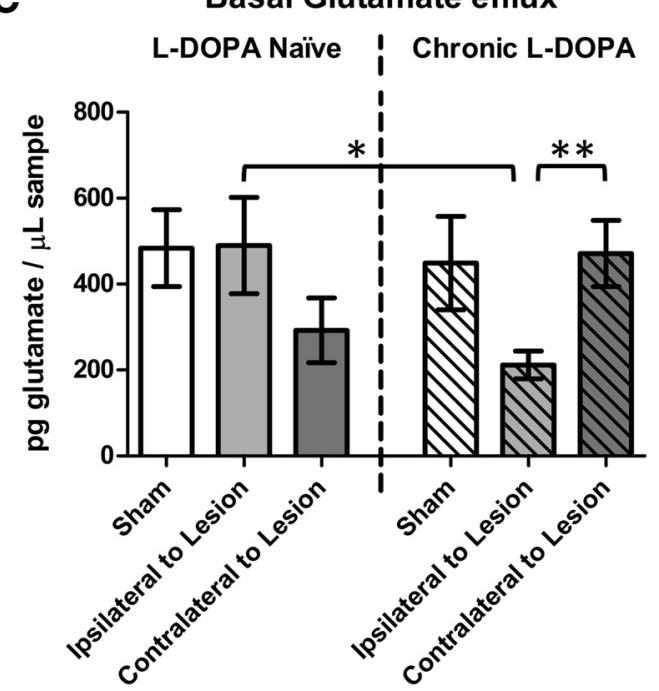

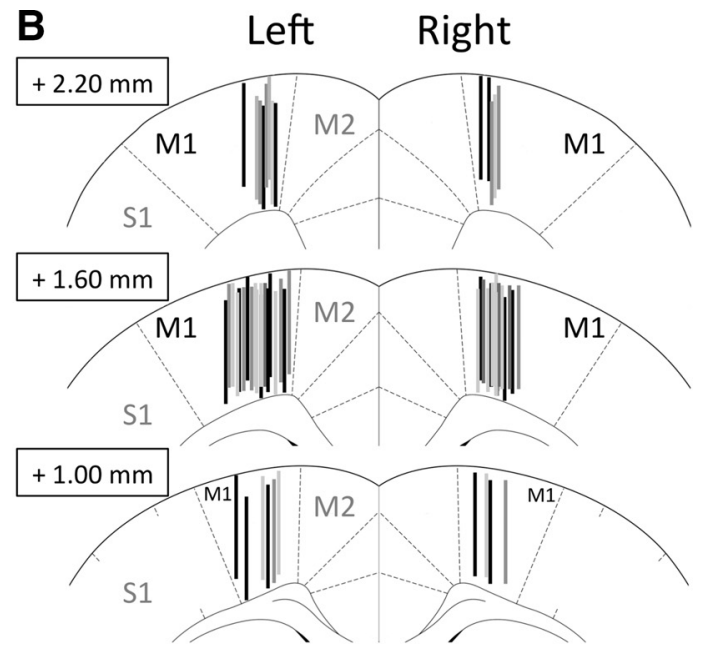

D Basal GABA efflux

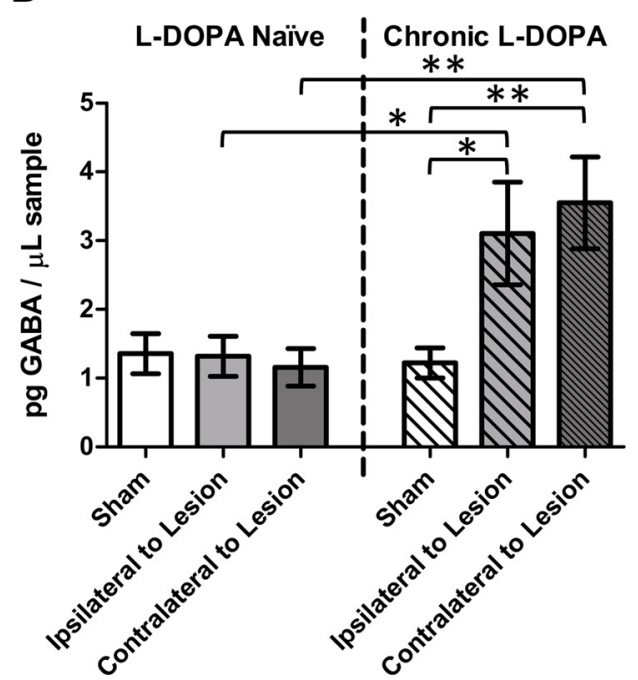

Figure 3. Effect of lesion and L-DOPA on basal (off-drug) efflux of glutamate and GABA in the primary motor cortex (M1; $n=11-16$ per group). $A$, Cresyl violet histology showing successful probe placement in M1. B, Schematic depicting all successful probe placements in M1. Also labeled are the adjacent medial cortices (supplementary motor: M2) and lateral cortices (primary somatosensory: S1). C, Average glutamate efflux among three baseline samples. $\boldsymbol{D}$, Average GABA efflux among three baseline samples. ${ }^{*} p<0.05 .{ }^{* *} p<0.01$.

protracted increase in GABA that was statistically significant at $140 \min (p=0.010)$. In M1 contralateral to lesion, acute L-DOPA did not affect GABA, but chronic L-DOPA caused an increase in GABA that was statistically significant at $100 \mathrm{~min}$ (Fig. $6 C ; p=0.036)$. Notably, L-DOPA-induced increases in GABA appeared to be temporally aligned between ipsilateral and contralateral to lesion (compare Fig. $6 B, C$ ).

Next, we correlated LID behavior with changes in M1 GABA efflux. There was a large positive correlation between GABA efflux and AIMs after acute L-DOPA; this correlation was stronger ipsilateral to lesion (Fig. 7A: $r^{2}=0.273, p<0.001$ ) than contralateral to lesion (Fig. $7 B ; r^{2}=0.082, p=0.010$ ). There was no correlation between AIMs and GABA efflux for rats given chronic L-DOPA (Fig. 7C,D).

Because GABA efflux correlated with LID behavior after acute L-DOPA, we performed a median split on the data splitting the rats into high and low AIMs groups (Fig. 7E). As with glutamate, no inferential statistics were performed. Comparing these groups, GABA levels increased above baseline for rats that expressed high AIMs, whereas GABA levels declined below baseline levels for rats that had low AIMs (Fig. 7F).
Experiment 2: contribution of $\mathrm{M} 1$ receptor signaling to behavioral output after systemic L-DOPA

Striatal tissue analysis

Striatal tissue was analyzed for monoamine content to verify 6-OHDA-induced DA depletion. As expected, there was more than a $99 \%$ depletion of striatal DA in the lesioned hemisphere compared with the intact hemisphere (19 vs $5141 \mathrm{pg} / \mathrm{mg}$ DA; $\left.t_{(70)}=16.85, p<0.001\right)$.

Effect of intra-M1 $D_{1}$ antagonism on PD and LID symptoms Analysis with the Friedman test revealed that microinjection of the $\mathrm{D}_{1}$ antagonist SCH23390 reduced dyskinesia scores $(n=12$; $\left.\chi^{2}=12.17, p=0.002\right)$. SCH23390 $18 \mathrm{nmol}$ was the only dose to significantly reduce AIMs compared with vehicle (Fig. $8 A$, inset; $Z=2.90, p=0.004)$, reducing AIMs scores at 80 and $110-120$ min after L-DOPA (Fig. $8 A$; all $p \leq 0.043$ ).

To determine whether M1 manipulations were broadly affecting motor function or specifically impacting LID behaviors, the FAS test was used $(n=15)$. First, we verified L-DOPA efficacy: percent intact stepping increased from $41 \%$ off-drug (before microinjections) to $61 \%$ on L-DOPA $4 \mathrm{mg} / \mathrm{kg}$ (after 
microinjection of vehicle; $t_{(14)}=2.70$, $p=0.017)$. Next, omnibus analyses of FAS scores after microinjection revealed a significant treatment effect $\left(F_{(2,28)}=\right.$ 4.08, $\left.p=0.028, \eta_{\mathrm{p}}^{2}=0.225\right)$. Planned comparisons revealed that SCH23390 18 nmol only reduced stepping compared with vehicle with the lesioned forelimb (Fig. $8 B ; t_{(14)}=3.12, p=$ $0.007)$, suggesting a reduction in L-DOPA efficacy by SCH23390.

Effect of intra-M1 NMDA antagonism on $P D$ and LID symptoms

Intra-M1 delivery of the NMDA antagonist MK-801 did not impact AIMs caused by L-DOPA $4 \mathrm{mg} / \mathrm{kg}$ (Fig. $9 A ; n=12$; $\chi^{2}=4.87, p=0.088$ ). As above, we verified L-DOPA efficacy by comparing percent intact stepping at baseline $(34 \%)$ to L-DOPA $4 \mathrm{mg} / \mathrm{kg}$ (62\%), which was a significant change $\left(t_{(13)}=6.35, p<0.001\right)$. Analysis of FAS scores showed no effects of treatment, suggesting that MK-801 treatment did not modify motor performance (Fig. 9B).

Effect of intra-M1 AMPA blockade on LID Blocking activity of AMPA glutamate receptors using NBQX significantly reduced AIMs scores $\left(n=13 ; \chi^{2}=6.62, p=\right.$ $0.037)$. NBQX $18 \mathrm{nmol}$ reduced LID compared with vehicle (Fig. 9C, inset; $Z=$ 2.34, $p=0.019$ ), but a significant reduction in LID was only observed at $100 \mathrm{~min}$ after L-DOPA (Fig. 9C; $p=0.049$ ).

We attempted to verify L-DOPA efficacy by comparing percent intact stepping off-drug $(37 \%)$ to percent intact on L-DOPA $4 \mathrm{mg} / \mathrm{kg}$ (55\%), but this difference was not statistically significant $\left(t_{(12)}=1.73, p=0.110\right)$. Examining FAS scores after microinjection, there was no effect of treatment, demonstrating that intra-M1 NBQX did not modify motor performance (Fig. 9D).

Effect of intra-M1 GABA $A_{A}$ activation on $P D$ and LID

In this cohort, we potentiated $\mathrm{GABA}_{\mathrm{A}}$ receptor activity using the selective agonist muscimol before L-DOPA $4 \mathrm{mg} / \mathrm{kg}$, resulting in a reduction of AIMs scores $(n=$ $\left.13 ; \chi^{2}=11.69, p=0.003\right)$. Overall, muscimol $18 \mathrm{nmol}$ reduced AIMs compared with vehicle (Fig. $10 A$, inset; $Z=2.98, p=0.003$ ), with significant reductions lasting from 50 to $100 \mathrm{~min}$ after L-DOPA (Fig. $10 \mathrm{~A}$; all $p \leq 0.041)$.

An increase in percent intact stepping between baseline (39\%) and L-DOPA $4 \mathrm{mg} / \mathrm{kg}$ (66\%) was taken as a validation of L-DOPA efficacy $\left(t_{(12)}=2.57, p=0.025\right)$. ANOVA analyses of FAS scores after muscimol showed an effect of treatment with muscimol $\left(F_{(2,24)}=18.01, p<0.001, \eta_{\mathrm{p}}^{2}=0.600\right)$ and a Treatment $\times$ Hemisphere interaction $\left(F_{(2,24)}=10.92, p=0.001, \eta_{\mathrm{p}}^{2}=0.462\right)$.
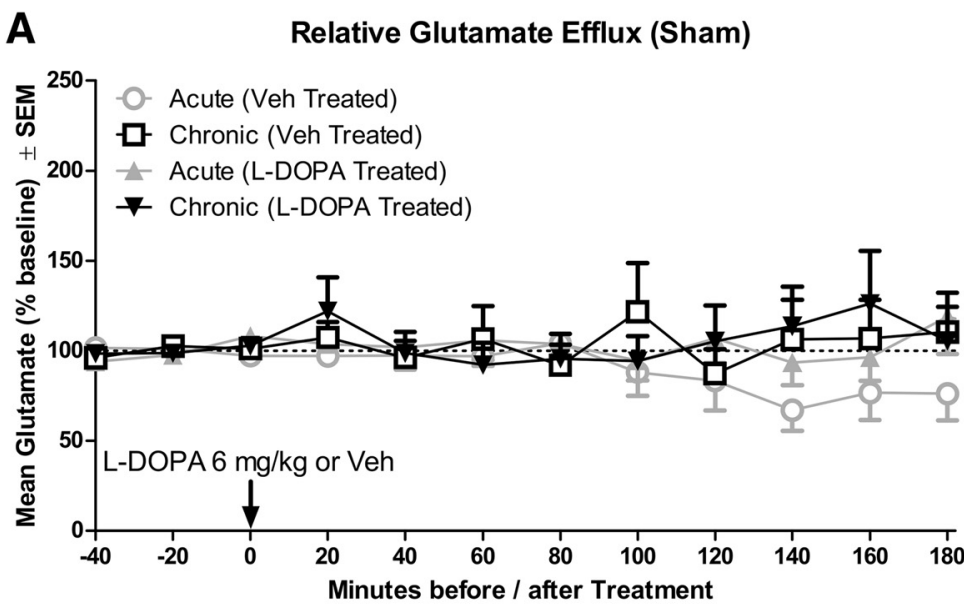

B Relative Glutamate Efflux (Ipsilateral to Lesion)

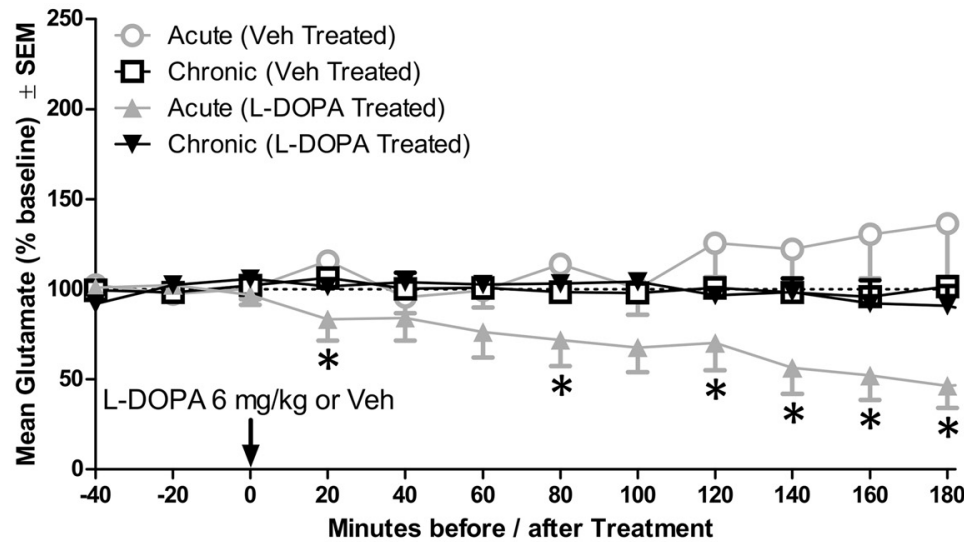

C Relative Glutamate Efflux (Contralateral to Lesion)

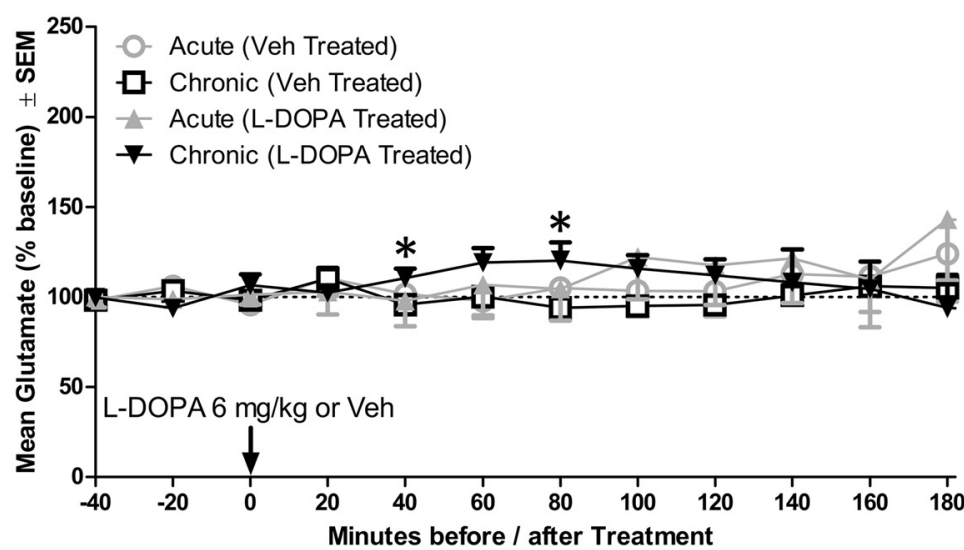

Figure 4. Change in primary motor cortex glutamate efflux as a result of acute or chronic L-DOPA treatment in sham and lesioned rats ( $n=10-16$ per group). $\boldsymbol{A}$, Glutamate efflux in sham rats. $\boldsymbol{B}$, Glutamate efflux ipsilateral to lesion. $\boldsymbol{C}$, Glutamate efflux contralateral to lesion. ${ }^{*} p<0.05$.

Muscimol did not affect stepping with the lesioned paw (Fig. $10 B)$. However, on the intact side, compared with vehicle, stepping was reduced by muscimol $18 \mathrm{nmol}\left(t_{(12)}=6.87, p<0.001\right)$ and $3 \mathrm{nmol}\left(t_{(12)}=2.28, p=0.041\right)$.

Effect of intra-M1 GABA $A_{B}$ activation on PD and LID

Given $\mathrm{GABA}_{\mathrm{A}}$ modulation of LID, we next examined the other major $\mathrm{GABA}$ receptor in the cortex, $\mathrm{GABA}_{\mathrm{B}}$, for effects on $\mathrm{PD}$ and LID behavior. Analysis of total AIMs using the Friedman 

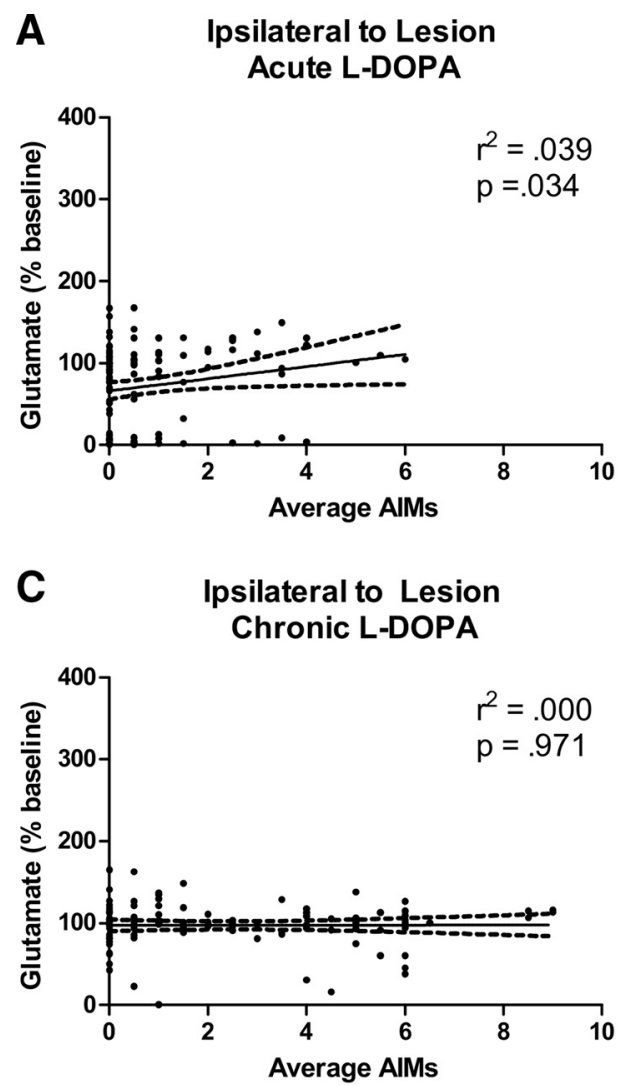

B

Contralateral to Lesion Acute L-DOPA

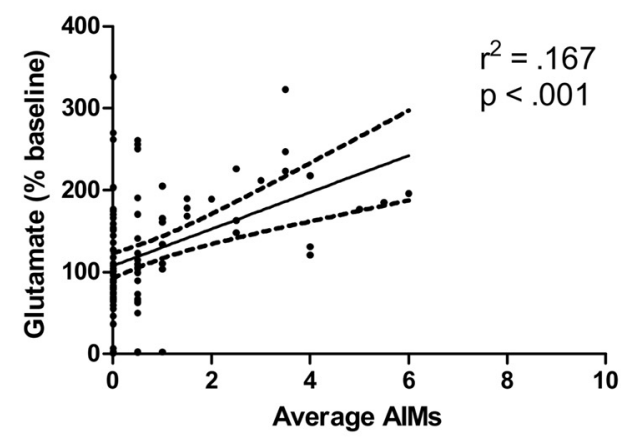

\section{Contralateral to Lesion} Chronic L-DOPA

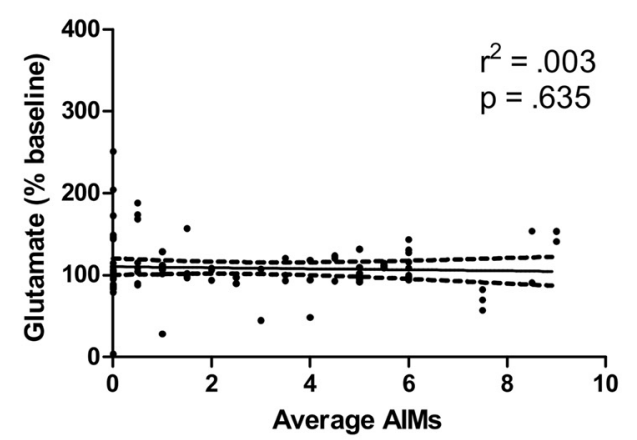

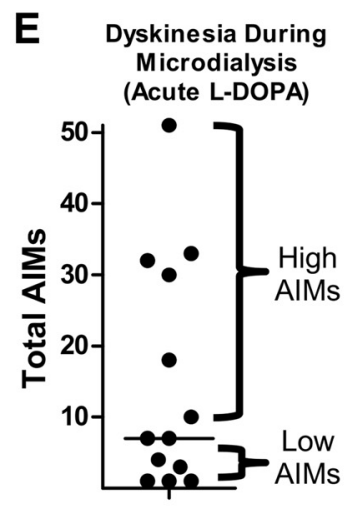

$\mathbf{F}$

Relative Glutamate Efflux (Acute L-DOPA)

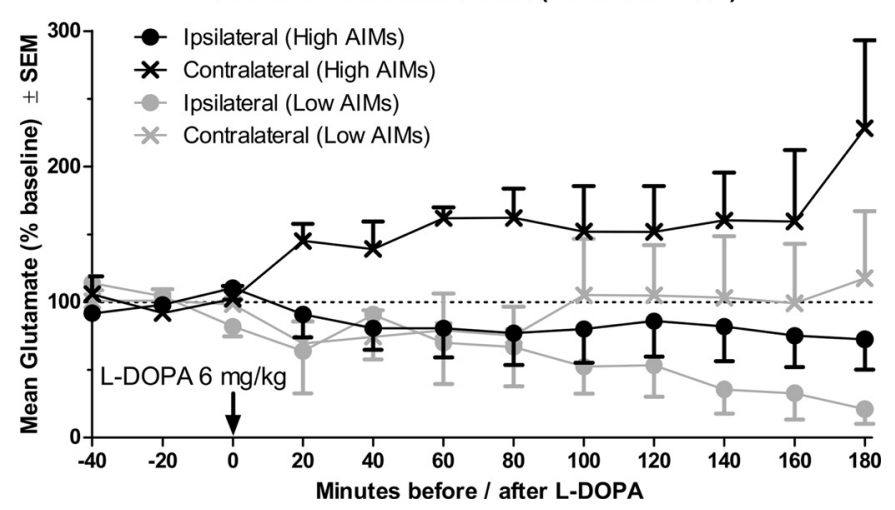

Figure 5. Relationship between change in primary motor cortex glutamate efflux and dyskinesia scores. $\boldsymbol{A}-\boldsymbol{D}$, Correlations between dyskinesia (assessed with the AIMs scale) and percentage baseline glutamate efflux. E, Median split of rats given acute L-DOPA into "high AIMs" and "low AIMs" groups. F, Glutamate efflux when acute L-DOPA-treated rats are split into high and low AIMs. Some rats have only one $\mathrm{M} 1$ probe $(n=4-6$ per group).

test revealed no effect of baclofen on dyskinesia (Fig. 10C; $n=$ $\left.12 ; \chi^{2}=0.17, p=0.920\right)$.

L-DOPA efficacy was verified in this cohort of rats by comparing percent intact stepping at baseline (28\%) and after L-DOPA $4 \mathrm{mg} / \mathrm{kg}\left(59 \% ; t_{(13)}=5.76, p<0.001\right)$. Analyses of FAS scores after baclofen revealed that baclofen reduced stepping overall $\left(F_{(2,26)}=19.28, p<0.001, \eta_{\mathrm{p}}^{2}=0.597\right)$ and there was a Hemisphere $\times$ Treatment interaction $\left(F_{(2,26}\right)=4.17$, $\left.p=0.027, \eta_{\mathrm{p}}^{2}=0.243\right)$. Baclofen $18 \mathrm{nmol}$ reduced stepping compared with vehicle with the intact forepaw (Fig. 10D; $\left.t_{(13)}=4.46, p=0.001\right)$, and a similar trend for reduced stepping was observed with the lesioned forepaw $\left(t_{(13)}=2.15\right.$, $p=0.051)$.

\section{Discussion}

This is the first experiment to provide evidence for changes in M1 amino acid release in an animal model of PD and LID (for a summary of results, see Tables 1-3). In nonlesioned rats, L-DOPA did not alter glutamate or GABA concentrations (Figs. 3C,D, 6A). In lesioned rats, $\mathrm{M} 1$ glutamate levels declined after acute L-DOPA, whereas chronic L-DOPA led to a long-term suppression of glutamate that was insensitive to further modulation (Figs. 3C, 4B). Notably, chronic L-DOPA preferentially enhanced GABA signaling (Figs. 3D, 6B). Dyskinesia was reduced by M1 delivery of a $D_{1}$ antagonist, an AMPA antagonist, or a $\mathrm{GABA}_{\mathrm{A}}$ agonist, suggesting that DA, glutamate, and GABA signaling in M1 all contribute to dyskinesia expression (Figs. $8 A, 9 C, 10 A$ ). 
Role of M1 glutamate in PD and LID For $>25$ years, canonical models of PD and LID have postulated that pathologically decreased M1 glutamate promotes PD symptoms whereas pathologically increased M1 glutamate promotes LID symptoms (Alexander et al., 1990; Cenci, 2007). Thus, it is surprising that 6-OHDA lesion alone did not reduce $\mathrm{M} 1$ glutamate efflux (Fig. 3C). Ipsilateral to lesion, the first exposure to L-DOPA caused glutamate levels to fall slowly but relatively continuously, declining to less than half of baseline levels after $3 \mathrm{~h}$ (Fig. 4B). Daily treatment with L-DOPA for $14 \mathrm{~d}$ reduced basal (off-drug) glutamate efflux, after which each L-DOPA injection no longer produced a change in glutamate. Thus, we provide convergent evidence that L-DOPA reduces M1 glutamate efflux, but it may do so in a protracted manner relative to brain levels of L-DOPA. Because there was no correlation between AIMs and glutamate efflux in rats given chronic L-DOPA (and no immediate change in glutamate efflux), we found no evidence for the involvement of glutamate in LID expression (Fig. 5C). Thus, our results fail to support the classical model of LID physiology wherein excessive M1 glutamate release is a key endogenous mediator of LID behavior (Obeso et al., 2000; Cenci, 2007).

At the same time, we provide evidence that M1 glutamate can function as a modulator of LID. Local M1 delivery of the AMPA antagonist NBQX was able to reduce dyskinesia, demonstrating that blunting M1 glutamate signaling can reduce LID (Fig. 9C). Although an NMDA antagonist alone did not significantly reduce LID (Fig. 9A), there is evidence that combined AMPA and NMDA antagonism produces more powerful LID suppression than can be achieved with blockade of either receptor alone (Bibbiani et al., 2005). Thus, our data do support the notion that targeting M1 glutamate signaling is a potential means to reduce LID.

One hypothesis is that long-term L-DOPA-induced reductions in M1 glutamate are important for the beneficial (promotor) effects of L-DOPA rather than in preventing LID. Indeed, long-term plasticity caused by L-DOPA is critical for therapeutic efficacy (Zhuang et al., 2013). Even after the benefits of L-DOPA were first reported, many clinicians remained skeptical about its utility because immediate effects are not evident in many patients (Cotzias et al., 1967; Fahn, 2015). In our experiment, the first dose of L-DOPA improved movement and reduced M1 glutamate efflux (Figs. $2 A, 4 B$ ). After chronic L-DOPA was withdrawn (for $>20 \mathrm{~h}$ ), rats showed improved movement indicative of L-DOPA-induced plasticity (Fig. 2A) (Zhuang et al., 2013) and had depressed basal M1 glutamate efflux (Fig. 3C), suggesting that the two ${ }^{*} p<0.05 .{ }^{* *} p<0.01$.

\section{A \\ Relative GABA Efflux (Sham)}

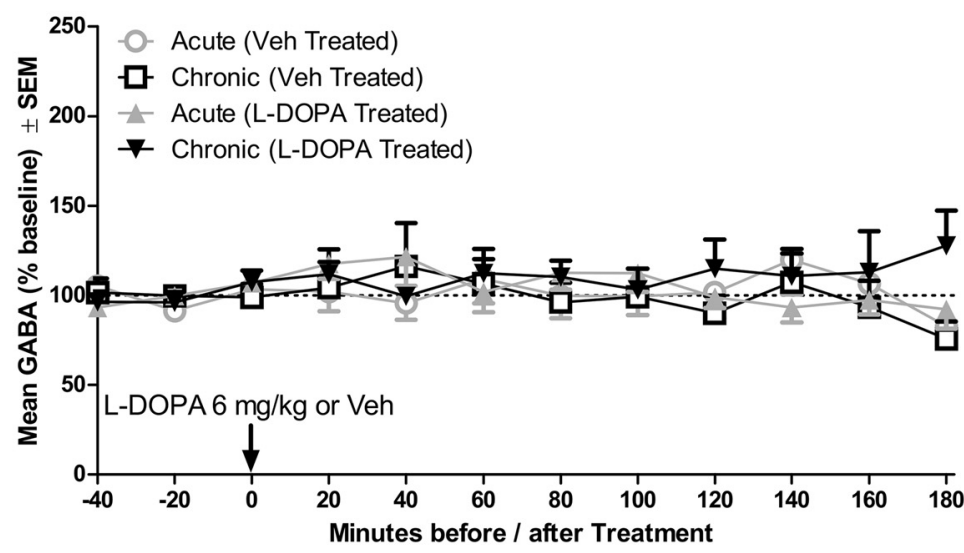

B Relative GABA Efflux (Ipsilateral to Lesion)

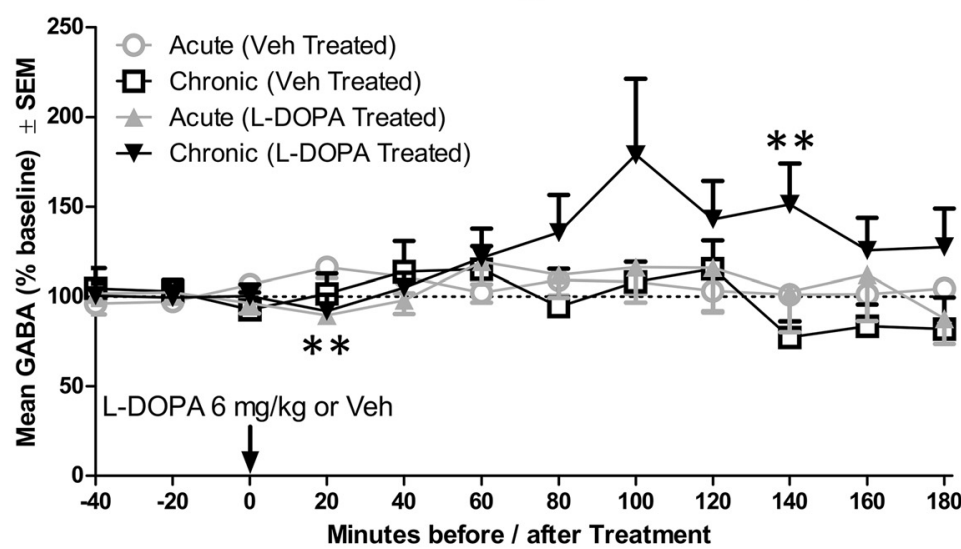

C Relative GABA Efflux (Contralateral to Lesion)

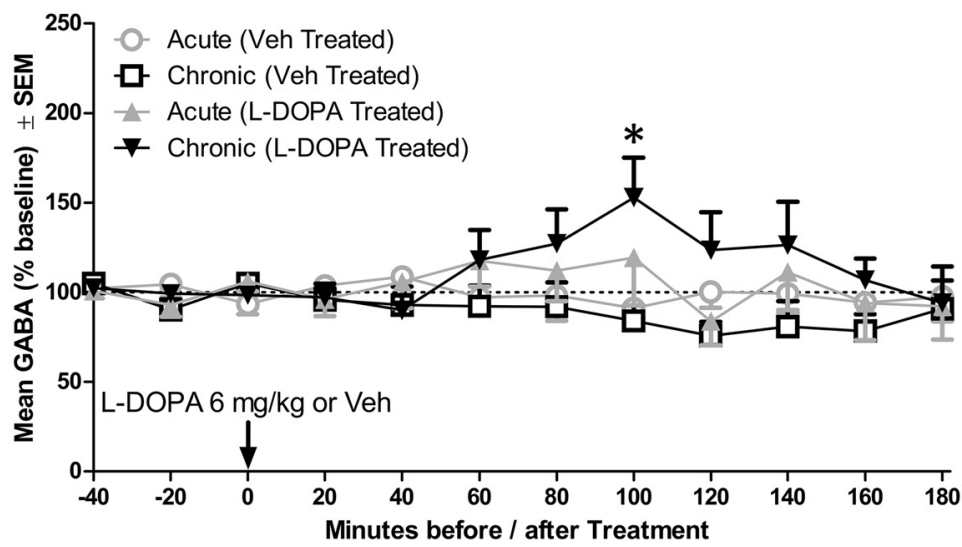

Figure 6. Change in primary motor cortex GABA efflux as a result of acute or chronic L-DOPA treatment in sham and lesioned rats ( $n=8-12$ per group). $\boldsymbol{A}$, GABA efflux in sham rats. $\boldsymbol{B}$, GABA efflux ipsilateral to lesion. $\boldsymbol{C}$, GABA efflux contralateral to lesion.

phenotypes might be causally linked. Together, our results support the general proposition that reducing glutamatergic activity in parkinsonian motor circuits is beneficial for relieving both PD and LID symptoms (Huot et al., 2013).

\section{Role of M1 GABA in PD and LID}

M1 GABA signaling has been implicated in PD pathophysiology because untreated PD patients often show deficient M1 GABAergic inhibition that is reversible by L-DOPA (Strafella et al., 2000; Chen et al., 2001; Lefaucheur, 2005). In the present experiment, 
A

Ipsilateral to Lesion

Acute L-DOPA

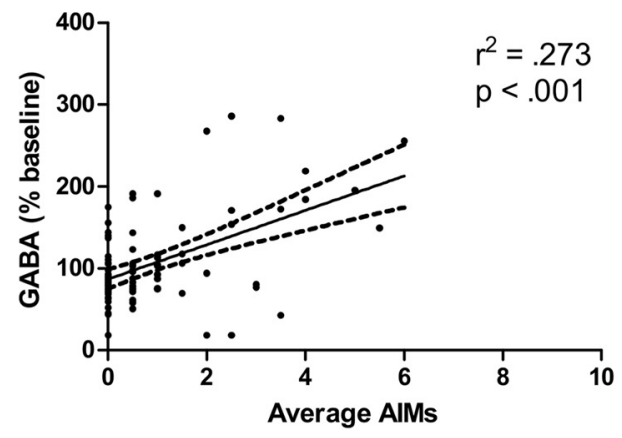

C

Ipsilateral to Lesion

Chronic L-DOPA

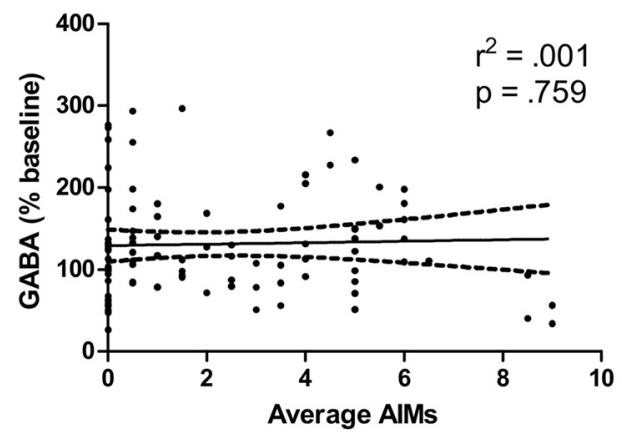

E

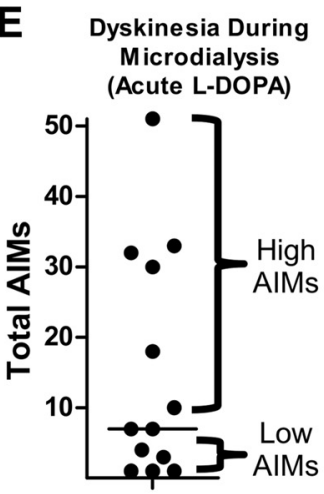

$\mathbf{F}$
B

Contralateral to Lesion Acute L-DOPA
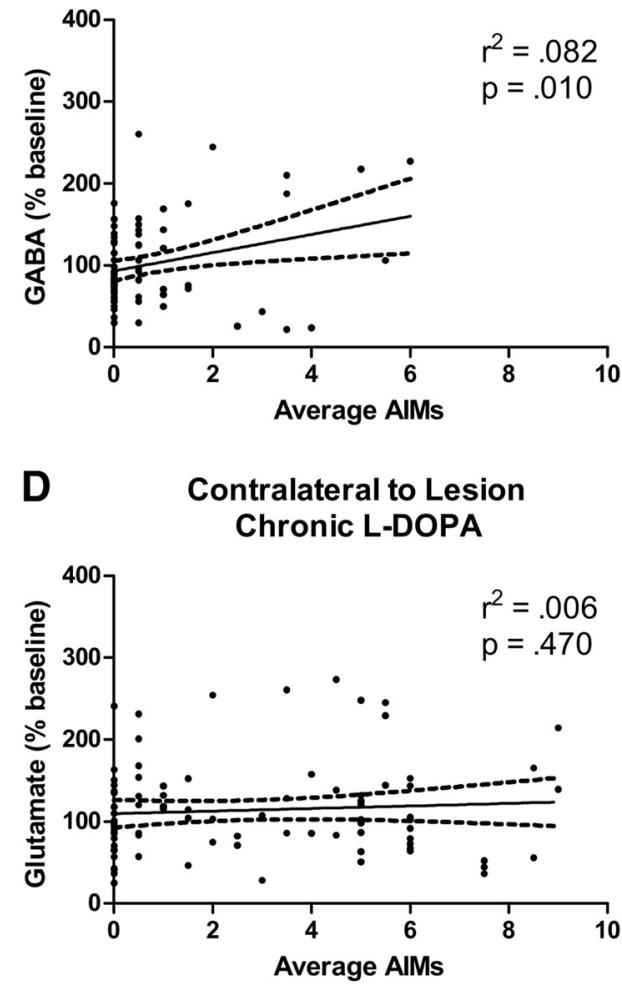

Relative GABA Efflux (Acute L-DOPA)

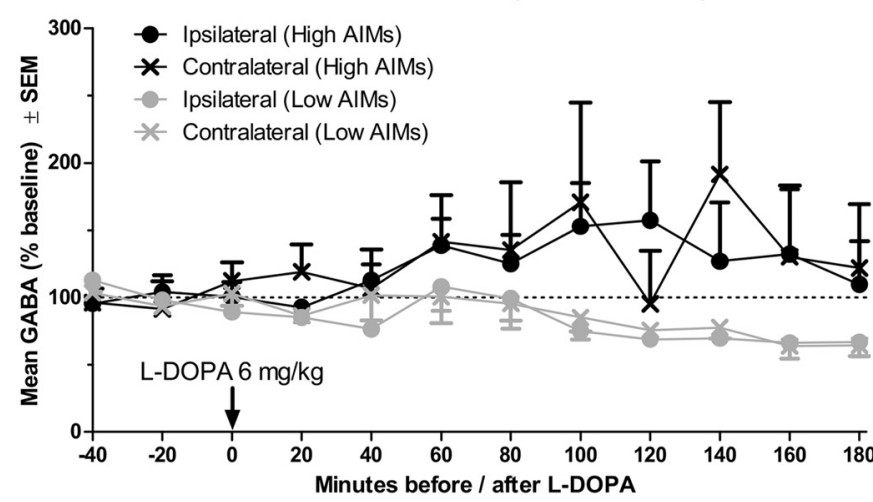

Figure 7. Relationship between change in primary motor cortex GABA efflux and dyskinesia scores. $A-D$, Correlations between dyskinesia (assessed with the AIMs scale) and percentage baseline GABA efflux. E, Median split of rats given acute L-DOPA into "high AIMs" and "low AIMs" groups. F, GABA efflux when acute L-DOPA-treated rats are split into high and low AIMs. Some rats have only one M1 probe ( $n=3-5$ per group).

as a singular manipulation, neither lesion nor chronic L-DOPA impacted basal GABA efflux (Figs. 3D, 6A). Instead, we observed an interaction between lesion and treatment: chronic L-DOPA increased basal GABA efflux bilaterally among unilaterally DAlesioned rats (Fig. 3D). Subsequent L-DOPA administration to these rats led to a further potentiation GABA efflux bilaterally, peaking numerically in both hemispheres $100 \mathrm{~min}$ after treatment (Fig. 6B,C). Thus, it appears that chronic L-DOPA increases GABA efflux in M1 across both short and long time scales.

In lesioned rats, changes in GABA efflux after L-DOPA administration were strongly correlated $\left(r^{2}=0.273\right)$ with LID behavior after acute, but not chronic, L-DOPA, suggesting that GABA may be involved in LID development (Fig. $7 A, C$ ). Overall, acute L-DOPA did not change GABA (Fig. 6B), but this was seemingly due to bidirectional modulation of GABA depending on LID status (Fig. $7 F$ ). Rats with relatively high AIMs after acute L-DOPA showed a temporal enhancement of GABA. By contrast, rats with low AIMs showed a slight decrease in GABA efflux after acute L-DOPA. Furthermore, the time course and magnitude of the increase in GABA among acutely L-DOPA-treated rats that expressed high AIMs (Fig. $7 F$ ) mirror the increase in GABA seen in chronically L-DOPA-treated rats (Fig. 6B), rats that also displayed similarly high AIMs (compare Figs. $2 B, 7 E$ ). These results provide convergent evidence that a rise in M1 GABA portends the expression of dyskinesia.

Because the increase in GABA after chronic L-DOPA occurred while LID was subsiding, M1 GABA induction after L-DOPA may ostensibly reduce LID (Figs. $2 C, 6 B$ ). In support of this notion, 
A Effect of $D_{1}$ Antagonist on L-DOPA-induced Dyskinesia

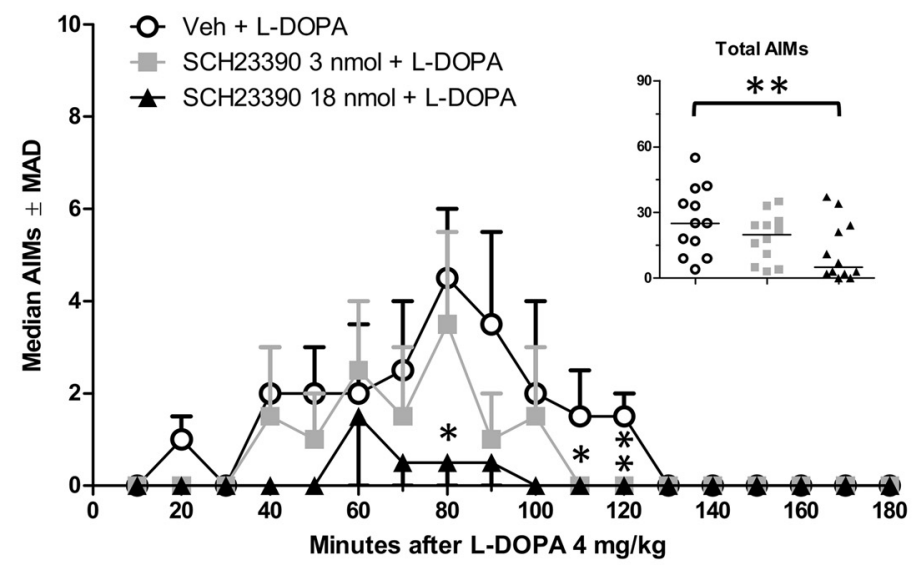

B

Effect of $D_{1}$ Antagonist on Motor Performance

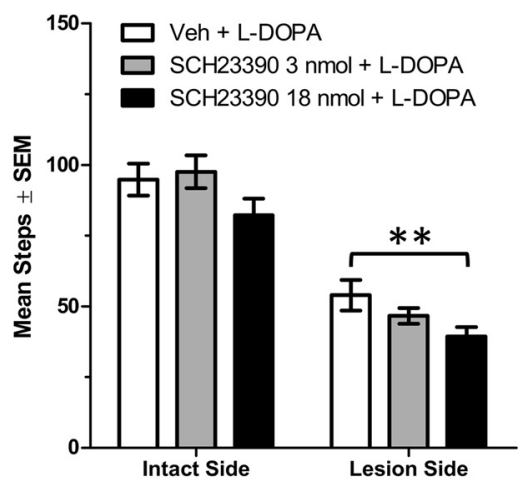

$60 \mathrm{~min}$ after microinjection / L-DOPA

Figure 8. Changes in the behavioral response to L-DOPA after microinjection of a $D_{1}$ receptor antagonist into the primary motor cortex. A, Dyskinesia assessed with the AIMs scale $(n=12)$. AlMs data are displayed as medians with median absolute deviation (MAD) as the error term. $\boldsymbol{B}$, Motor performance assessed with the FAS test $(n=15) .{ }^{*} p<0.05$. ${ }^{* *} p<0.01$.

\section{A Effect of NMDA Antagonist on L-DOPA-induced Dyskinesia}

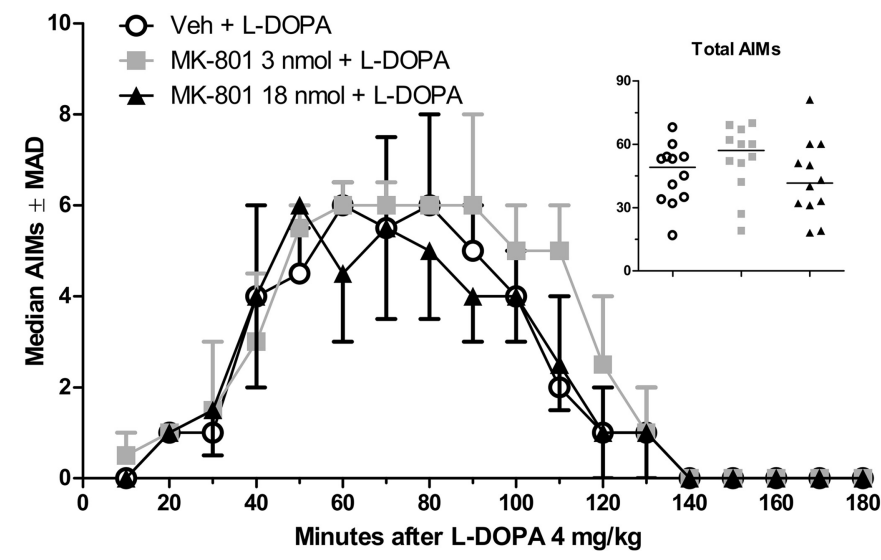

C Effect of AMPA Antagonist on L-DOPA-induced Dyskinesia

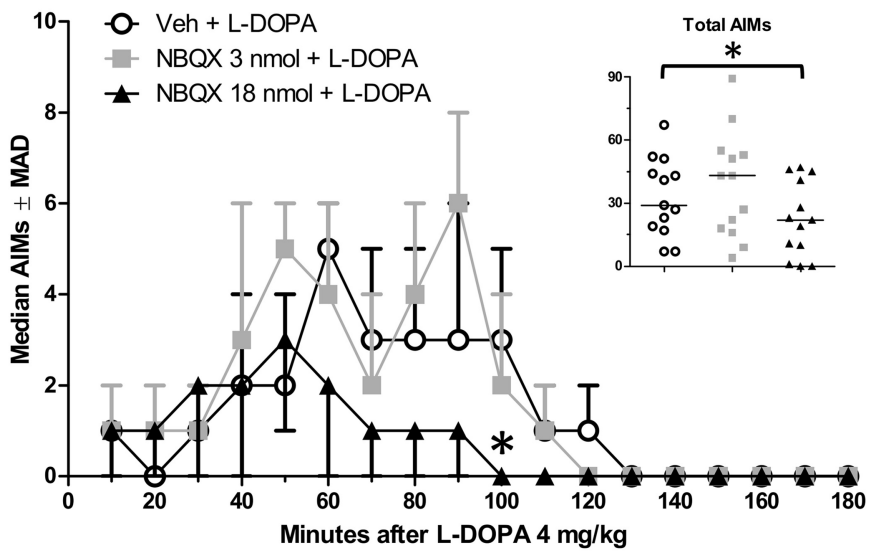
B Effect of NMDA Antagonist

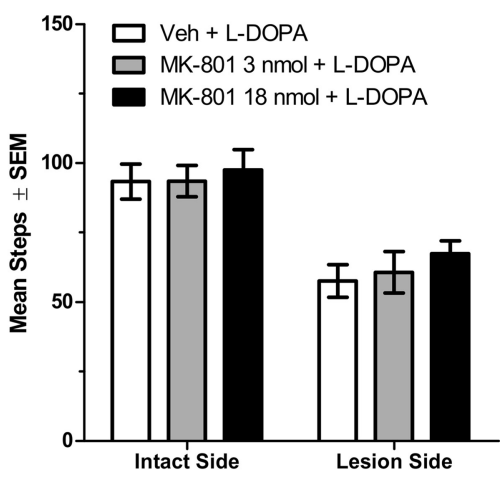

60 min after microinjection / LDOPA
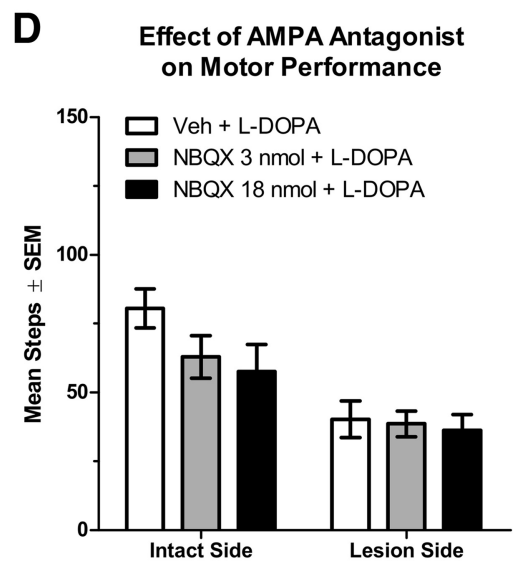

60 min after microinjection / L-DOPA

Figure 9. Changes in the behavioral response to L-DOPA after microinjection of an AMPA or NMDA receptor antagonist into the primary motor cortex. $A$, Dyskinesia assessed with the AIMs scale $(n=12)$ after NMDA blockade. $\boldsymbol{B}$, Motor performance assessed with the FAS test ( $n=15)$ after NMDA blockade (C) Dyskinesia assessed with the AIMs scale after AMPA blockade $(n=12)$. D, Motor performance assessed with the FAS test after AMPA blockade $(n=15)$. AlMs data are displayed as medians with median absolute deviation (MAD) as the error term. ${ }^{*} p<0.05$.

potentiating GABA signaling via microinjection of the $\mathrm{GABA}_{\mathrm{A}}$ agonist muscimol into M1 caused a consistent suppression of LID from 50 to $100 \mathrm{~min}$ after L-DOPA (Fig. 10A). This suggests that increasing inhibitory $\mathrm{GABA}_{\mathrm{A}}$ tone in $\mathrm{M} 1$ is a powerful means of controlling LID. This proposition is reinforced by clinical re- search showing that inhibitory (low-frequency) M1 transcranial magnetic stimulation significantly reduces LID (Wagle-Shukla et al., 2007; Filipović et al., 2009).

We found no evidence for a causal link between the promotor effects of L-DOPA and increased M1 GABA signaling. 
A Effect of $\mathrm{GABA}_{\mathrm{A}}$ Agonist on L-DOPA-induced Dyskinesia

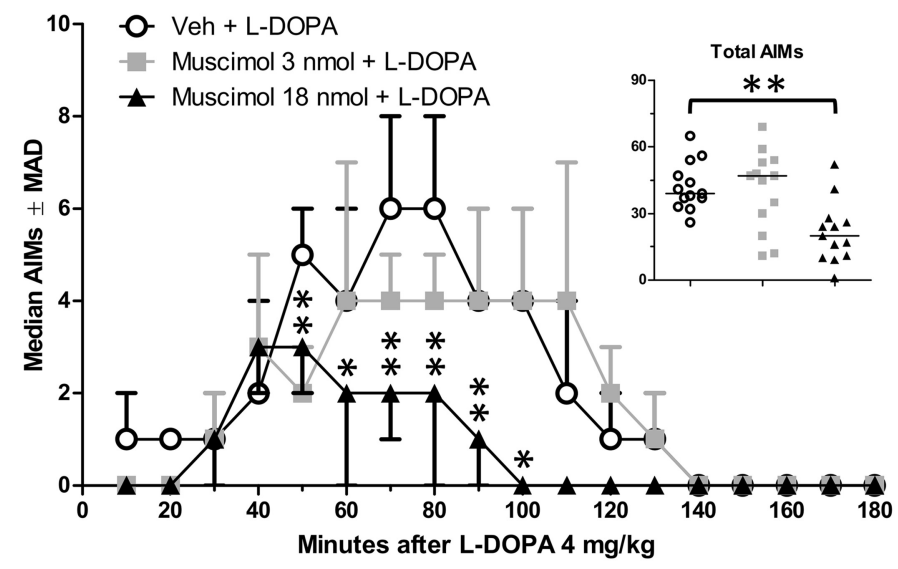

C Effect of GABA ${ }_{B}$ Agonist on L-DOPA-induced Dyskinesia

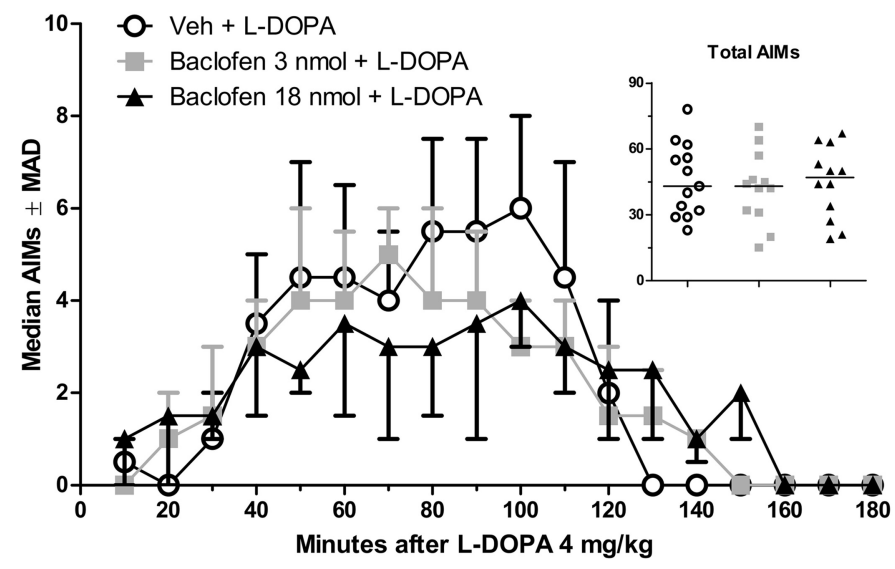

B

\section{Effect of GABA A Agonist on Motor Performance}

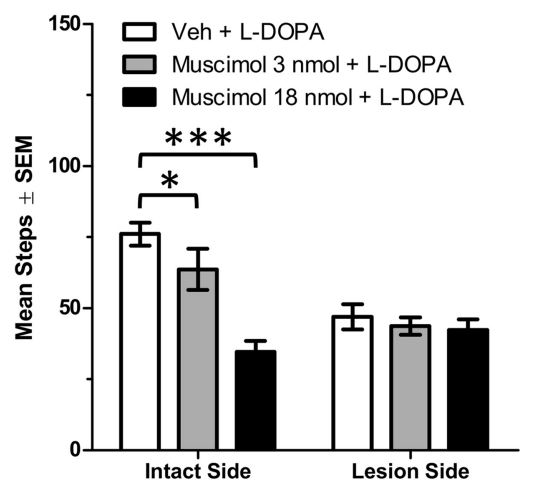

60 min after microinjection / L-DOPA

D

\section{Effect of GABA $B$ Agonist on Motor Performance}

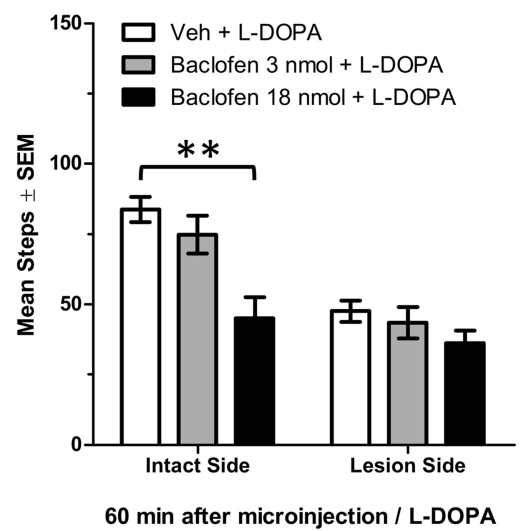

Figure 10. Changes in the behavioral response to L-DOPA after microinjection of a $G_{A B A}$ or $G A B A_{B}$ agonist into the primary motor cortex. $A$, Dyskinesia assessed with the AIMs scale after $G A B A_{A}$ activation $(n=13)$. $\boldsymbol{B}$, Motor performance assessed with the FAS test after $\mathrm{GABA}_{\mathrm{A}}$ activation $(n=14)$. $\boldsymbol{C}$, Dyskinesia assessed with the AlMs scale after GABA $\mathrm{B}_{B}$ activation $(n=12)$. $\boldsymbol{D}$, Motor performance assessed with the FAS test after $\mathrm{GABA}_{B}$ activation $(n=15)$. AlMs data are displayed as medians with median absolute deviation $(\mathrm{MAD})$ as the error term. ${ }^{*} p<0.05 .{ }^{* *} p<0.01$. ${ }^{* * *} p<0.001$.

Table 1. Long-term changes in basal M1 glutamate and GABA efflux caused by chronic L-DOPA ${ }^{a}$

\begin{tabular}{llc}
\hline Lesion status & Glutamate & GABA \\
\hline Sham & - & - \\
Ipsilateral to lesion & $\downarrow$ & $\uparrow$ \\
Contralateral to lesion & - & $\uparrow$ \\
\hline
\end{tabular}

$\overline{{ }^{a} \text { Changes in basal amino acid efflux (pg of glutamate or GABA/ } \mu \text { l of dialysate) as a result of chronic L-DOPA were }}$ dependent on the presence of a 6 -hydroxydopamine lesion. $\uparrow$, increase in neurotransmitter concentration versus treatment-naive subjects; $\downarrow$, decrease in neurotransmitter concentration versus treatment-naive subjects.

Both muscimol and baclofen reduced motor performance with the intact, but not lesioned, forelimb (Fig. $10 B, D$ ). This leads to the novel conclusion that healthy motor systems require an intact M1 GABA system to facilitate rapid forelimb movement. Likewise, it appears that forelimb movement in a parkinsonian motor system is less sensitive to perturbations in M1 GABA signaling, although we cannot rule out the possibility that a floor effect on the behavioral scale led to the perception of a null effect. When given acute L-DOPA, M1 GABA levels only rose for a subset of rats with high AIMs, but (in different rats) L-DOPA provided the same degree of pro-motor benefit on day 1 as on day 10 (compare Figs. $2 A, 7 F)$. Because the GABA system sensitized to chronic L-DOPA but the pro-motor benefit did not, our work does not provide clear evidence for their causal association.
Table 2. Short-term changes in M1 glutamate and GABA efflux immediately after L-DOPA ${ }^{a}$

\begin{tabular}{llll}
\hline Lesion status & Treatment & Glutamate & GABA \\
\hline Sham & Acute L-DOPA & - & - \\
Ipsilateral to lesion & Acute L-DOPA & $\downarrow$ & $\downarrow$ or $^{b} \uparrow$ \\
Contralateral to lesion & Acute L-DOPA & $\downarrow$ or $^{b} \uparrow$ & - \\
Sham & Chronic L-DOPA & - & - \\
Ipsilateral to lesion & Chronic L-DOPA & - & $\uparrow$ \\
Contralateral to lesion & Chronic L-DOPA & $\uparrow$ & $\uparrow$ \\
\hline
\end{tabular}

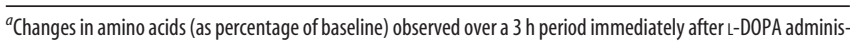
tration.

${ }^{b}$ Modulation appeared to depend upon the severity of dyskinesia displayed by the rat (see Figs. 5F, 7F).

Involvement of $\mathrm{D}_{1}$ receptors in $\mathrm{M} 1$

Microinjection of the $\mathrm{D}_{1}$ antagonist $\mathrm{SCH} 23390$ reduced dyskinesia evoked by systemic L-DOPA (Fig. $8 A$ ), in agreement with similar findings by Halje et al. (2012). In combination with systemic L-DOPA, SCH23390 reduced motor performance with the lesioned, but not intact, forelimb, suggesting that $D_{1}$ receptors in $\mathrm{M} 1$ contribute to the pro-motor effects of L-DOPA, in addition to modulating dyskinetic behavior (Fig. $8 B$ ). Previous research has implicated $\mathrm{M} 1 \mathrm{D}_{1}$ receptors in motor learning (Molina-Luna et al., 2009), but we are the first to show that they are also involved 
Table 3. Modulation of L-DOPA-induced behavioral effects by M1 microinjections ${ }^{a}$

\begin{tabular}{lcll}
\hline M1 microinfusion & Dyskinesia & $\begin{array}{l}\text { Intact limb motor } \\
\text { performance }\end{array}$ & $\begin{array}{l}\text { Lesioned limb motor } \\
\text { performance }\end{array}$ \\
\hline$D_{1}$ antagonist & $\downarrow$ & - & $\downarrow$ \\
NMDA antagonist & - & - & - \\
AMPA antagonist & $\downarrow$ & - & - \\
GABA $_{A}$ agonist & $\downarrow$ & $\downarrow$ & - \\
$\mathrm{GABA}_{\mathrm{B}}$ agonist & - & $\downarrow$ & - \\
\hline
\end{tabular}

$\bar{a}$ In lesioned rats, M1 microinjection of various agonists and antagonists affected behavioral output caused by systemic L-DOPA. $\downarrow$, Decrease in dyskinesia severity or decrease in motor performance.

in motor performance, specifically in the ability to rapidly initiate and terminate movement, as measured by the FAS test. This finding parallels research in the striatum showing that $D_{1}$ receptor activation contributes to both the positive and negative effects of L-DOPA (Jenner, 2008; Huot et al., 2013).

\section{Involvement of M1 contralateral to 6-OHDA lesion}

Glutamate and GABA efflux were dynamically altered by L-DOPA in M1 contralateral to 6-OHDA lesion, even though sham-lesioned rats showed no such changes. This is surprising given that our laboratory recently reported that M1 monoamine tissue concentrations are equivalent between shams and contralateral to lesion (Lindenbach et al., 2015). In the present investigation, we observed that L-DOPA increased both glutamate and GABA efflux contralateral to 6-OHDA lesion (albeit on different time scales) after chronic L-DOPA as well as after acute L-DOPA among rats with relatively high dyskinesia (Figs. 4C, 5F, 6C, $7 F$ ). Because these alterations were exclusively observed in rats that expressed motor symptoms of LID, movement-associated changes may account for the observed differences in M1 signaling. A second possibility is that M1 ipsilateral to lesion is disrupting amino acid signaling contralateral to lesion via transcollosal fibers in layer II/III. Indeed, there is evidence for bilateral changes in corticostriatal activity among unilaterally lesioned rats, and these changes may be relevant for translational medicine because PD patients manifest symptoms unilaterally during early disease stages (Jankovic, 2008; Massie et al., 2010; Lieu and Subramanian, 2012). Changes occurring in the nonsymptomatic brain hemisphere of PD patients may serve to mask motor symptoms and thus merit further investigation.

In conclusion, our results demonstrate that L-DOPA increases inhibitory tone in $\mathrm{M} 1$ regardless of LID status. In this respect, the observed reductions in glutamate and increases in GABA suggest a neurochemical basis for the consistent, but surprising, observation that L-DOPA reduces global M1 activation in PD patients with or without LID (Hershey et al., 1998; Haslinger et al., 2001; Asanuma et al., 2006). While local GABAergic interneurons provide the principle source of GABA to $\mathrm{M} 1$, the source of alterations in glutamate remains elusive because the $2 \mathrm{~mm}$ dialysis probe used in the present experiment ostensibly sampled from all 2.4 $\mathrm{mm}$ of rat cortex (Paxinos and Watson, 1998). Although it is tempting to speculate that basal ganglia modulation of thalamocortical activity reduces $\mathrm{M} 1$ glutamate release, $\mathrm{M} 1$ also receives corticocortical glutamate projections from the sensory cortices, supplementary motor regions, prefrontal areas, and the contralateral M1 (Lindenbach and Bishop, 2013). Future studies will need to dissect the cortical loci of alterations in glutamate and GABA signaling.

Perhaps the most important question raised by the present work is whether the endogenous changes in M1 signaling occurring during LID act to promote or inhibit the expression of LID. In the present experiment, L-DOPA increased measurements of
M1 inhibitory tone, by either suppressing glutamate release (after acute L-DOPA: Fig. $4 B$ ) or by enhancing GABA release (after chronic L-DOPA: Fig. $6 B$ ). Furthermore, we were able to reduce LID with an M1 microinjection of three compounds that, by their actions, should reduce neuron firing rates: an AMPA antagonist, a $\mathrm{D}_{1}$ antagonist, and a $\mathrm{GABA}_{\mathrm{A}}$ agonist (Figs. $8 A, 9 C, 10 A$ ).

The present data are generally consistent with the notion that the magnitude of excitatory signaling in M1 tracks positively with LID severity (Tables 1-3). The sole exception is that increases in GABA efflux were positively correlated with dyskinesia severity after acute L-DOPA (Fig. 7A). However, even these data are consistent with the notion that increases in endogenous M1 inhibition observed during LID may be a means of compensating for basal ganglia dysfunction. Exogenously reducing M1 activity likely reduces LID by potentiating the endogenous response to L-DOPA. To this end, we provide further support for the emerging notion that low-frequency (inhibitory) transcranial magnetic stimulation is a valid therapeutic strategy for reducing LID (Wagle-Shukla et al., 2007; Filipović et al., 2009).

\section{References}

Ahlskog JE, Muenter MD (2001) Frequency of levodopa-related dyskinesias and motor fluctuations as estimated from the cumulative literature. Mov Disord 16:448-458. CrossRef Medline

Ahmed I, Bose SK, Pavese N, Ramlackhansingh A, Turkheimer F, Hotton G, Hammers A, Brooks DJ (2011) Glutamate NMDA receptor dysregulation in Parkinson's disease with dyskinesias. Brain 134:979-986. CrossRef Medline

Alexander GE, Crutcher MD, DeLong MR (1990) Basal ganglia-thalamocortical circuits: parallel substrates for motor, oculomotor, "prefrontal" and "limbic" functions. Prog Brain Res 85:119-146. Medline

Asanuma K, Tang C, Ma Y, Dhawan V, Mattis P, Edwards C, Kaplitt MG, Feigin A, Eidelberg D (2006) Network modulation in the treatment of Parkinson's disease. Brain 129:2667-2678. CrossRef Medline

Bastide MF, Dovero S, Charron G, Porras G, Gross CE, Fernagut PO, Bézard E (2014) Immediate-early gene expression in structures outside the basal ganglia is associated to L-DOPA-induced dyskinesia. Neurobiol Dis 62:179-192. CrossRef Medline

Bibbiani F, Oh JD, Kielaite A, Collins MA, Smith C, Chase TN (2005) Combined blockade of AMPA and NMDA glutamate receptors reduces levodopa-induced motor complications in animal models of PD. Exp Neurol 196:422-429. CrossRef Medline

Brazhnik E, Cruz AV, Avila I, Wahba MI, Novikov N, Ilieva NM, McCoy AJ, Gerber C, Walters JR (2012) State-dependent spike and local field synchronization between motor cortex and substantia nigra in hemiparkinsonian rats. J Neurosci 32:7869-7880. CrossRef Medline

Carlezon WA Jr, Wise RA (1996) Rewarding actions of phencyclidine and related drugs in nucleus accumbens shell and frontal cortex. J Neurosci 16:3112-3122. Medline

Cenci MA (2007) Dopamine dysregulation of movement control in L-DOPA-induced dyskinesia. Trends Neurosci 30:236-243. CrossRef Medline

Cenci MA, Lundblad M (2007) Ratings of L-DOPA-induced dyskinesia in the unilateral 6-OHDA lesion model of Parkinson's disease in rats and mice. Curr Protoc Neurosci 9:25. CrossRef Medline

Cenci MA, Ohlin KE, Odin P (2011) Current options and future possibilities for the treatment of dyskinesia and motor fluctuations in Parkinson's disease. CNS Neurol Disord Drug Targets 10:670-684. CrossRef Medline

Chang JW, Wachtel SR, Young D, Kang UJ (1999) Biochemical and anatomical characterization of forepaw adjusting steps in rat models of Parkinson's disease: studies on medial forebrain bundle and striatal lesions. Neuroscience 88:617-628. CrossRef Medline

Chen R, Kumar S, Garg RR, Lang AE (2001) Impairment of motor cortex activation and deactivation in Parkinson's disease. Clin Neurophysiol 112:600-607. CrossRef Medline

Cotzias GC, Van Woert MH, Schiffer LM (1967) Aromatic amino acids and modification of parkinsonism. N Engl J Med 276:374-379. CrossRef Medline

Dupre KB, Ostock CY, Eskow Jaunarajs KL, Button T, Savage LM, Wolf W, 
Bishop C (2011) Local modulation of striatal glutamate efflux by serotonin $1 \mathrm{~A}$ receptor stimulation in dyskinetic, hemiparkinsonian rats. Exp Neurol 229:288-299. CrossRef Medline

Dupre KB, Ostock CY, George JA, Eskow Jaunarajs KL, Hueston CM, Bishop C (2013) Effects of 5-HT receptor stimulation on D1 receptor agonistinduced striatonigral activity and dyskinesia in hemiparkinsonian rats. ACS Chem Neurosci 4:747-760. CrossRef Medline

Eskow KL, Gupta V, Alam S, Park JY, Bishop C (2007) The partial 5-HT1A agonist buspirone reduces the expression and development of L-DOPAinduced dyskinesia in rats and improves L-DOPA efficacy. Pharmacol Biochem Behav 87:306-314. CrossRef Medline

Fahn S (2015) The medical treatment of Parkinson disease from James Parkinson to George Cotzias. Mov Disord 30:4-18. CrossRef Medline

Filipović SR, Rothwell JC, van de Warrenburg BP, Bhatia K (2009) Repetitive transcranial magnetic stimulation for levodopa-induced dyskinesias in Parkinson's disease. Mov Disord 24:246-253. CrossRef Medline

Fregni F, Simon DK, Wu A, Pascual-Leone A (2005) Non-invasive brain stimulation for Parkinson's disease: a systematic review and meta-analysis of the literature. J Neurol Neurosurg Psychiatry 76:1614-1623. CrossRef Medline

Gaspar P, Duyckaerts C, Alvarez C, Javoy-Agid F, Berger B (1991) Alterations of dopaminergic and noradrenergic innervations in motor cortex in Parkinson's disease. Ann Neurol 30:365-374. CrossRef Medline

Halje P, Tamtè M, Richter U, Mohammed M, Cenci MA, Petersson P (2012) Levodopa-induced dyskinesia is strongly associated with resonant cortical oscillations. J Neurosci 32:16541-16551. CrossRef Medline

Haslinger B, Erhard P, Kämpfe N, Boecker H, Rummeny E, Schwaiger M, Conrad B, Ceballos-Baumann AO (2001) Event-related functional magnetic resonance imaging in Parkinson's disease before and after levodopa. Brain 124:558-570. CrossRef Medline

Hershey T, Black KJ, Stambuk MK, Carl JL, McGee-Minnich LA, Perlmutter JS (1998) Altered thalamic response to levodopa in Parkinson's patients with dopa-induced dyskinesias. Proc Natl Acad Sci U S A 95:1201612021. CrossRef Medline

Huot P, Johnston TH, Koprich JB, Fox SH, Brotchie JM (2013) The pharmacology of L-DOPA-induced dyskinesia in Parkinson's disease. Pharmacol Rev 65:171-222. CrossRef Medline

Jankovic J (2008) Parkinson's disease: clinical features and diagnosis. J Neurol Neurosurg Psychiatry 79:368-376. CrossRef Medline

Jenner P (2008) Molecular mechanisms of L-DOPA-induced dyskinesia. Nat Rev Neurosci 9:665-677. CrossRef Medline

Kawaguchi K, Simon RP (1997) Deep prepiriform cortex modulates neuronal cell death in global ischemia. J Cereb Blood Flow Metab 17:356-360. CrossRef Medline

Kilpatrick IC, Jones MW, Phillipson OT (1986) A semiautomated analysis method for catecholamines, indoleamines, and some prominent metabolites in microdissected regions of the nervous system: an isocratic HPLC technique employing coulometric detection and minimal sample preparation. J Neurochem 46:1865-1876. CrossRef Medline

La Bella V, Piccoli F (2000) Differential effect of beta-N-oxalylamino-Lalanine, the Lathyrus sativus neurotoxin, and (+/-)-alpha-amino-3hydroxy-5-methylisoxazole-4-propionate on the excitatory amino acid and taurine levels in the brain of freely moving rats. Neurochem Int 36:523-530. CrossRef Medline

Lefaucheur JP (2005) Motor cortex dysfunction revealed by cortical excitability studies in Parkinson's disease: influence of antiparkinsonian treatment and cortical stimulation. Clin Neurophysiol 116:244-253. CrossRef Medline

Lefaucheur JP (2009) Treatment of Parkinson's disease by cortical stimulation. Expert Rev Neurother 9:1755-1771. CrossRef Medline

Lieu CA, Subramanian T (2012) The interhemispheric connections of the striatum: implications for Parkinson's disease and drug-induced dyskinesias. Brain Res Bull 87:1-9. CrossRef Medline

Lindenbach D, Bishop C (2013) Critical involvement of the motor cortex in the pathophysiology and treatment of Parkinson's disease. Neurosci Biobehav Rev 37:2737-2750. CrossRef Medline

Lindenbach D, Ostock CY, Eskow Jaunarajs KL, Dupre KB, Barnum CJ, Bhide N, Bishop C (2011) Behavioral and cellular modulation of L-DOPAinduced dyskinesia by $\beta$-adrenoceptor blockade in the 6-hydroxydopamine-lesioned rat. J Pharmacol Exp Ther 337:755-765. CrossRef Medline

Lindenbach D, Conti MM, Ostock CY, Dupre KB, Bishop C (2015) Altera- tions in primary motor cortex neurotransmission and gene expression in hemi-parkinsonian rats with drug-induced dyskinesia. Neuroscience 310: 12-26. CrossRef Medline

Mabrouk OS, Semaan DZ, Mikelman S, Gnegy ME, Kennedy RT (2014) Amphetamine stimulates movement through thalamocortical glutamate release. J Neurochem 128:152-161. CrossRef Medline

Martin JH (1991) Autoradiographic estimation of the extent of reversible inactivation produced by microinjection of lidocaine and muscimol in the rat. Neurosci Lett 127:160-164. CrossRef Medline

Massie A, Schallier A, Vermoesen K, Arckens L, Michotte Y (2010) Biphasic and bilateral changes in striatal VGLUT1 and 2 protein expression in hemi-Parkinson rats. Neurochem Int 57:111-118. CrossRef Medline

Molina-Luna K, Pekanovic A, Röhrich S, Hertler B, Schubring-Giese M, Rioult-Pedotti MS, Luft AR (2009) Dopamine in motor cortex is necessary for skill learning and synaptic plasticity. PloS One 4:e7082.

Obeso JA, Rodriguez-Oroz MC, Rodriguez M, Lanciego JL, Artieda J, Gonzalo N, Olanow CW (2000) Pathophysiology of the basal ganglia in Parkinson's disease. Trends Neurosci [Suppl] 23:S8-S19. CrossRef Medline

Ohlin KE, Sebastianutto I, Adkins CE, Lundblad C, Lockman PR, Cenci MA (2012) Impact of L-DOPA treatment on regional cerebral blood flow and metabolism in the basal ganglia in a rat model of Parkinson's disease. Neuroimage 61:228-239. CrossRef Medline

Ostock CY, Dupre KB, Jaunarajs KL, Walters H, George J, Krolewski D, Walker PD, Bishop C (2011) Role of the primary motor cortex in L-DOPA-induced dyskinesia and its modulation by 5 -HT1A receptor stimulation. Neuropharmacology 61:753-760. CrossRef Medline

Ostock CY, Hallmark J, Palumbo N, Bhide N, Conti M, George JA, Bishop C (2015) Modulation of L-DOPA's antiparkinsonian and dyskinetic effects by alpha2-noradrenergic receptors within the locus coeruleus. Neuropharmacology 95:215-225. CrossRef Medline

Parr-Brownlie LC, Hyland BI (2005) Bradykinesia induced by dopamine D2 receptor blockade is associated with reduced motor cortex activity in the rat. J Neurosci 25:5700-5709. CrossRef Medline

Pasquereau B, Turner RS (2011) Primary motor cortex of the parkinsonian monkey: differential effects on the spontaneous activity of pyramidal tract-type neurons. Cereb Cortex 21:1362-1378. CrossRef Medline

Paxinos G, Watson C (1998) The rat brain in stereotaxic coordinates, Ed 4. San Diego: Academic.

Rea K, Cremers TI, Westerink BH (2005) HPLC conditions are critical for the detection of GABA by microdialysis. J Neurochem 94:672-679. CrossRef Medline

Ridding MC, Inzelberg R, Rothwell JC (1995) Changes in excitability of motor cortical circuitry in patients with Parkinson's disease. Ann Neurol 37:181-188. CrossRef Medline

Rowley HL, Martin KF, Marsden CA (1995) Determination of in vivo amino acid neurotransmitters by high-performance liquid chromatography with o-phthalaldehyde-sulphite derivatisation. J Neurosci Methods 57:93-99. CrossRef Medline

Sorg BA, Li N, Wu WR (2001) Dopamine D1 receptor activation in the medial prefrontal cortex prevents the expression of cocaine sensitization. J Pharmacol Exp Ther 297:501-508. Medline

St-Pierre JA, Bédard PJ (1994) Intranigral but not intrastriatal microinjection of the NMDA antagonist MK-801 induces contralateral circling in the 6-OHDA rat model. Brain Res 660:255-260. CrossRef Medline

Strafella AP, Valzania F, Nassetti SA, Tropeani A, Bisulli A, Santangelo M, Tassinari CA (2000) Effects of chronic levodopa and pergolide treatment on cortical excitability in patients with Parkinson's disease: a transcranial magnetic stimulation study. Clin Neurophysiol 111:1198-1202. CrossRef Medline

Wagle-Shukla A, Angel MJ, Zadikoff C, Enjati M, Gunraj C, Lang AE, Chen R (2007) Low-frequency repetitive transcranial magnetic stimulation for treatment of levodopa-induced dyskinesias. Neurology 68:704-705. CrossRef Medline

Wu AD, Fregni F, Simon DK, Deblieck C, Pascual-Leone A (2008) Noninvasive brain stimulation for Parkinson's disease and dystonia. Neurotherapeutics 5:345-361. CrossRef Medline

Yu H, Sternad D, Corcos DM, Vaillancourt DE (2007) Role of hyperactive cerebellum and motor cortex in Parkinson's disease. Neuroimage 35: 222-233. CrossRef Medline

Zhuang X, Mazzoni P, Kang UJ (2013) The role of neuroplasticity in dopaminergic therapy for Parkinson disease. Nat Rev Neurol 9:248-256. CrossRef Medline 